\title{
Effects of Specific Cochlear Pathologies on the Auditory Functions: Modelling, Simulations and Clinical Implications
}

\author{
Amin G. Saremi
}

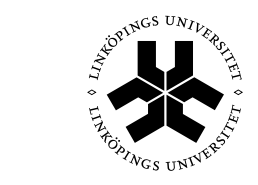

Linköping University

Linköping University Medical Disserations No. 1400

Studies from the Swedish Institute for Disability Research No. 60

Division of Technical Audiology

Department of Clinical and Experimental Medicine

Faculty of Health Sciences,

Linköping 2014 
Studies from the Swedish Institute for Disability Research No. 60

Vid filosofiska fakulteten vid Linköpings universitet bedrivs forskning och ges forskarutbildning med utgångspunkt från breda problemområden. Forskningen är organiserad i mångvetenskapliga forskningsmiljöer och forskarutbildningen huvudsakligen i forskarskolor. Gemensamt ger de ut serien Linköping Studies in Arts and Science. Denna avhandling kommer från Teknisk Audiologi vid Institutionen för Klinisk och Experimentell Medicin.

Distribueras av:

Institutionen för Klinisk och Experimentell Medicin, Linköpings universitet,

58183 Linköping.

Amin G. Saremi

Effects of Specific Cochlear Pathologies on the Auditory Functions: Modelling, Simulations and Clinical Implications.

Upplaga 1:1

ISBN: 978-91-7519-365-6

ISSN: $1650-1128$

ISSN: 0345-0082

(c)Amin G. Saremi

Institutionen för Klinisk och Experimentell Medicin, 2014.

Omslagsbild: ๑ Olivier Cros, Institutionen för Medicinsk Teknik. Tryckeri: Liu-Tryck, Linköping, 2014. 
Optimus Parentibus 



\section{POPULÄRVETENSKAPLIG SAMMANFATTNING}

Idag diagnostiseras en hörselnedsättning i första hand av patientens audiogram. Beroende på hur grav hörselnedsättningen är rekommenderas patienten hörapparatutprovning eller inte. Däremot påvisar inte ett audiogram, som enbart bygger på patientens förmåga att höra svaga toner (hörtrösklar), de specifikt skadade strukturerna i hörselsystemet. Hörselsnäckan (koklean) är en del av innerörat och ansvarar för många nyckelfunktioner i hörselsystemet som neural kodning av det inkommande ljudet. Dessutom uppkommer de vanligaste förekommande typer av hörselnedsättning i hörselsnäckan. Syftet med detta projekt var att skapa en biologiskt baserad modell av människans hörselsnäcka för att simulera hur vissa innerörapatologier påverkar auditiva funktioner. De patologier som studerats är ålderrelaterad hörselnedsättning (presbyacusis) och bullertrauma. Projektet innehåller även en klinisk studie som syftar till att jämföra resultaten från kliniska test (t.ex. audiometri) med simuleringsmodellens förutsägelse. Detta för att bättre kunna identifiera mekanismer i hörselsnäckan som är associerade med bullertrauma respektive åldersrelaterad hörselnedsättning. Denna studie innehåller 7 olika psykoakustiska, fysiologiska och kognitiva test som genomfördes på 47 deltagare på hörselkliniken vid Linköpings Universitetssjukhus. Studien visade att modellen väl predicerade resultaten från den kliniska studien. Projektet är ett multidisciplinärt arbete i det avseende att det sammanlänkar biologiska processer på cellnivå med akustisk modellering och klinisk audiologi. 



\section{SUMMARY OF PAPERS}

PAPER I: Amin Saremi and Stefan Stenfelt (2011). "A physiological signal transmission model to be used for specific diagnosis of cochlear impairments," American Institute of Physics, 1403, 369-373.

PAPER II: Amin Saremi and Stefan Stenfelt (2012). "Effect of ageing on the cochlear amplifier: A simulation approach using a physiologically-based elctromechanical model of the human cochlea, " Journal of Canadian Acoustics, 40 (3), pp. 128-129.

PAPER III: Amin Saremi and Stenfelt Stefan (2013). "Effect of metabolic presbyacusis on cochlear responses: A simulation approach using a physiologically-based model, " Journal of the Acoustical Society of America, 134 (4), pp. 2833-2852.

PAPER IV: Amin Saremi and Stefan Stenfelt (2014). "Effects of Acoustic Overstimulation and the Associated Cellular Lesions on the Cochlear Amplifier: Simulation Results, ". Status: Submitted to the Journal of the Acoustical Society of America.

PAPER V: Amin Saremi, Elina Mäki-Torkko and Stefan Stenfelt (2014). "Changes in Temporal and Spectral Functions of the Auditory Periphery Due to Aging and Noise-induced Cochlear Pathologies: A Comparative Clinical Study, ".

Status: Manuscript. 
The aim of this thesis is to simulate the effects of specific pathologies in the human inner ear, caused by ageing and acoustic overstimulation, on the auditory processing. A major part of the present thesis is dedicated to modelling the mammalian cochlear structures and biophysical processes in form of a physiologically-based signal transmission line. It is shown that the model is capable of reproducing the experimental data recorded from aged and noisedamaged animal cochleae. Furthermore, to validate the clinical implications of the modelling work for humans, the final part of the thesis is allocated to a clinical study comprising of psychoacoustic, physiological and cognitive tests.

Paper I presents the principles of lumped-element modelling, the mechanical elements of the model, and the equivalent electrical analogy. It also describes mathematically how the longitudinal coupling along the human cochlear structures can be estimated based on the recordings from passive cadaver cochleae.

Paper II and III simulate the effects of the age-related strial degenerations (metabolic presbyacusis) on the characteristics of the cochlear responses. Paper II briefly introduces the schematic of the model including passive structures and active mechanisms. It also quantifies the decline of the cochlear amplification due to metabolic presbyacusis.

The model is further developed in paper III, where a detailed description of the model elements and parameter values is presented. Paper III reports the decline of the frequency response and temporal coding of the cochlea as well as the changes in the functionality of the inner hair cell - auditory nerve synapse due to metabolic presbyacusis. It also shows that the model predictions closely match with the experimental data recorded from aged and furosemide-treated gerbils.

Paper IV, on the other hand, focuses on simulating the effects of the cochlear lesions associated with acoustic overstimulation. It investigates the changes in the loudness growth caused by noise-induced deficiency of the mechanoelectrical transduction channels. Furthermore, it quantifies the decline of the cochlear amplifier as a result of outer hair cell death at specific regions of the cochlear duct. The simulation results are compared with the experimental data recoded from noise-damaged mice cochleae.

Finally, Paper V presents the clinical study comprising a test battery of psychoacoustic, physiological and cognitive tests. Three groups of subjects participated in the study: normal hearing, presbyacusis and noise-damaged. The clinical results are collated and compared with the model predictions demonstrating a reasonable agreement. 
"If you cannot make a model, you did not understand" Lord Kelvin (1824-1907) 



\section{TABLE OF CONTENTS}

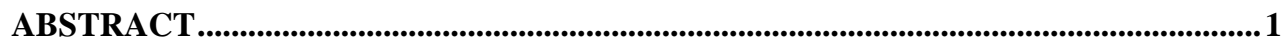

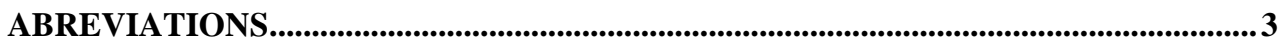

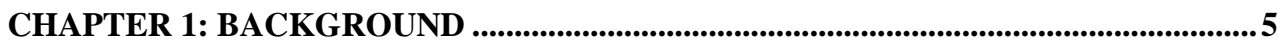

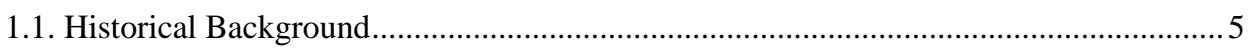

1.2. A Brief Introduction to Anatomy of Cochlea............................................................... 6

1.2.1. The lateral wall of cochlea and stria vascularis ......................................................

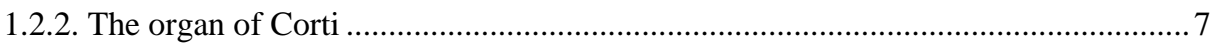

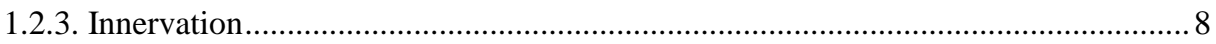

1.3. Sensorineural Hearing Impairment and Inner-ear Pathologies ....................................... 8

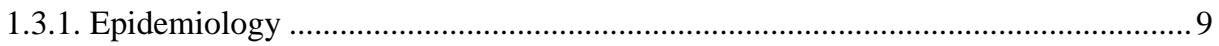

1.4. Auditory Modelling: Computational Models vs. Physiologically-based Models ......... 10

CHAPTER 2: THE MODEL ...................................................................................13

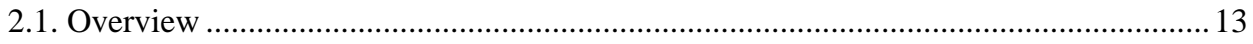

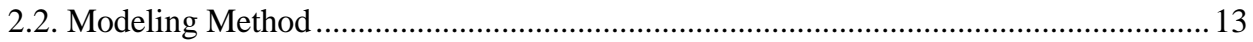

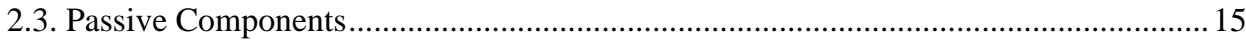

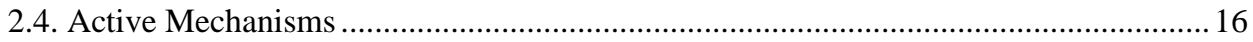

2.4.1. Stria vascularis: The biological power supply of the cochlea …………………..... 16

2.4.2. Mechanoelectrical transduction: the driver of the somatic motor ............................ 16

2.4.3. The somatic motor: the OHC's molecular motor for generating active forces .......18

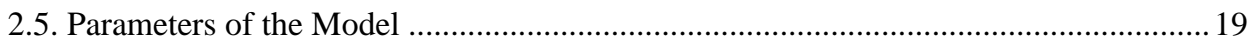

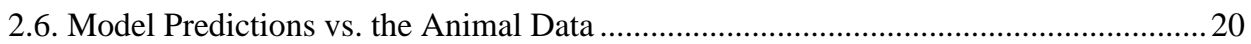

CHAPTER 3: BIOPHYSICS OF THE AGING COCHLEA .............................................21

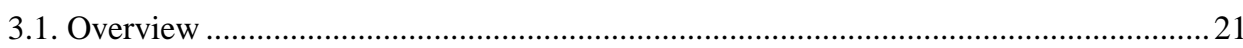

3.2. How Does Aging Manipulate the Cochlear System? …………………………........ 21

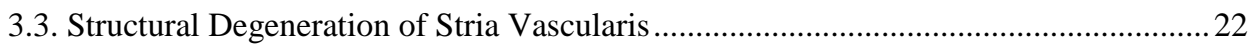

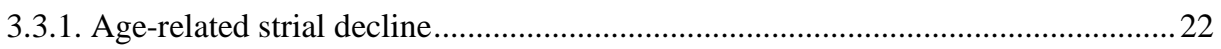

3.3.2. Effects of metabolic disorders on the structural integrity of stria vascularis ........22

3.4. Changes in Cochlear Responses due to Metabolic Presbyacusis ................................... 23

3.4.1. Effects of metabolic presbyacusis on the cochlear amplifier.................................23

3.4.2. Effects of metabolic presbyacusis on the temporal coding of the cochlea ............24

3.4.3. Effects of metabolic presbyacusis on the tuning pattern of the cochlea ................24

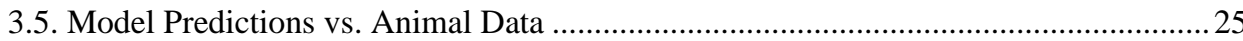




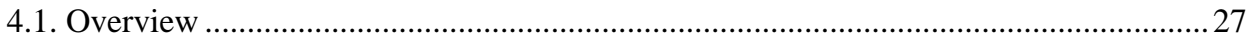

4.2. How Does Acoustic Overstimulation Manipulate the Cochlear System?.....................27

4.3. Effects of Noise-induced Lesions on the Cochlear Amplifier ......................................28

4.3.1. Effects of MET deficiency on the cochlear amplifier..........................................28

4.3.2. Effects of the damages to the OHCs on the cochlear amplifier ............................. 30

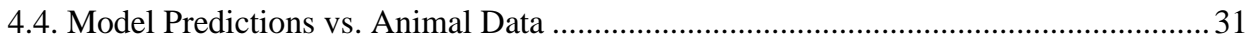

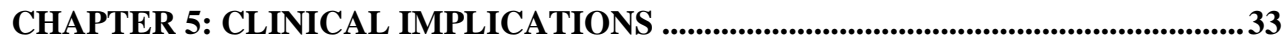

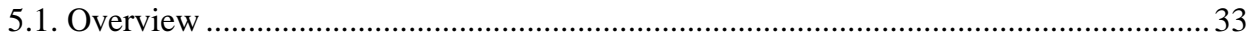

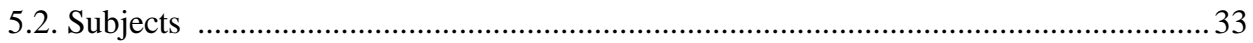

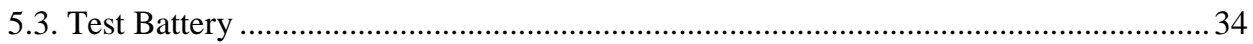

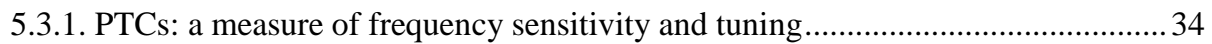

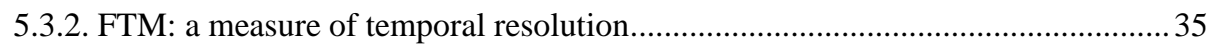

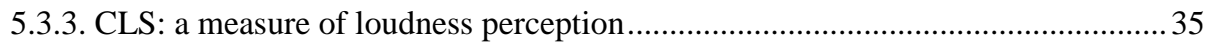

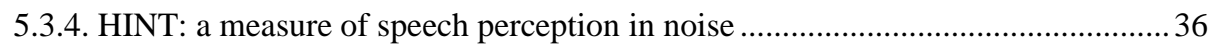

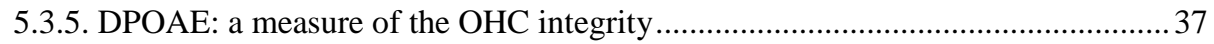

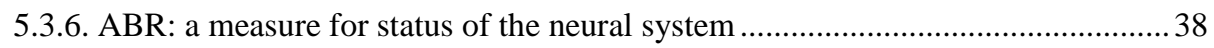

5.3.7. Reading-span test: a measure of the working-memory capacity .......................... 38

5.4. Clinical Results vs. Model Predictions ......................................................................... 39

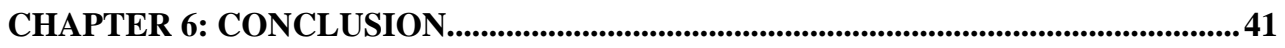

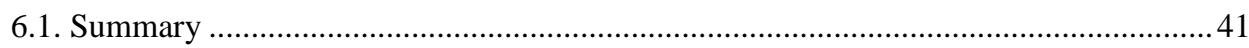

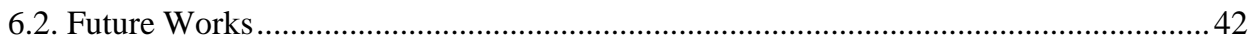

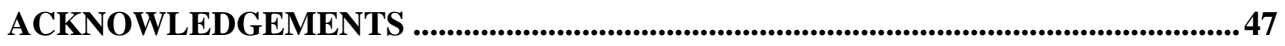

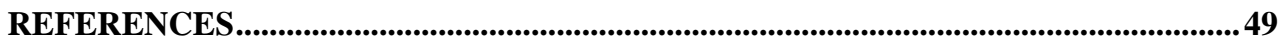




\begin{abstract}
A hearing impairment is primarily diagnosed by measuring the hearing thresholds at a range of auditory frequencies (air-conduction audiometry). Although this clinical procedure is simple, affordable, reliable and fast, it does not offer differential information about origins of the hearing impairment. The main goal of this thesis is to quantitatively link specific cochlear pathologies to certain changes in the spectral and temporal characteristics of the auditory system. This can help better understand the underlying mechanisms associated with sensorineural hearing impairments, beyond what is shown in the audiogram. Here, an electromechanical signal-transmission model is devised in MATLAB where the parameters of the model convey biological interpretations of mammalian cochlear structures. The model is exploited to simulate the cell-level cochlear pathologies associated with two common types of sensorineural hearing impairments, 1: presbyacusis (age-related hearing impairment) and, 2: noise-induced hearing impairment. The simulations demonstrate that the age-related degeneration of stria vascularis results in reduction of the cochlear amplification and decline of frequency sensitivity. It also results in inhibition of the firing rate of the auditory nerve leading to impaired temporal coding. Furthermore, the simulations show that the noiseinduced changes in micromechanics of the stereocillia result in impaired growth of loudness reminiscent of the 'recruitment phenomenon'. Moreover, various conditions were simulated whereby the acoustic overstimulation was assumed severe enough to directly damage the outer hair cells at specific regions of the cochlear duct. The results depict a mild loss at low frequencies followed by a notch-like dip at frequencies between 3 and $4 \mathrm{kHz}$. It is shown that the model is capable of reproducing the experimental data recorded from aged and noisedamaged animal cochleae. Furthermore, a clinical study, consisting of different psychoacoustic and physiological tests, was performed to trace and validate the model predictions in human. The results of the clinical tests were collated and compared with the model predictions, showing a reasonable agreement. In summary, the present model provides a biophysical foundation for simulating the effect of specific cellular lesions, due to different inner-ear diseases and external insults, on the entire cochlear and thereby the whole auditory system. This is a multidisciplinary work in the sense that it connects the 'biological processes' with 'acoustic modelling' and 'clinical audiology' in a translational context.
\end{abstract}



ABREVIATIONS

\begin{tabular}{|l|l|}
\hline BM & Basilar Membrane \\
\hline RL & Reticular Lamina \\
\hline OHC & Outer Hair Cell \\
\hline IHC & Inner Hair Cell \\
\hline TM & Tectorial Membrane \\
\hline HB & Hair Bundle \\
\hline EP & Endocochlear Potential \\
\hline MET & MechanoElectrical Transduction \\
\hline AN & Auditory Nerve \\
\hline HSR & High Spontaneous Rate \\
\hline MSR & Medium Spontaneous Rate \\
\hline LSR & Low Spontaneous Rate \\
\hline ARHL & Age-Related Hearing Loss \\
\hline NIHL & Noise-Induced Hearing Loss \\
\hline CAP & Compound Action Potential \\
\hline DPOAE & Distortion Product OtoAcoustic Emissions \\
\hline ABR & Auditory Brainstem Responses \\
\hline PTC & Psychoacoustic Tuning Curves \\
\hline FTM & Forward Temporal Masking \\
\hline CLS & Catagorical Loudness Scaling \\
\hline HINT & Hearing-In-Noise Test \\
\hline
\end{tabular}





\section{BACKGROUND}

\subsection{Historical Background}

Acoustics is a multi-disciplinary translational science that studies mechanical waves propagating in physical media (i.e., gases, liquids and solids) in form of sound, ultrasound and infrasound. The word acoustics takes root from the Greek word akoustos meaning 'audible' although modern acoustics also includes inaudible mechanical vibrations, infrasound and ultrasound (Guthrie, 1978).

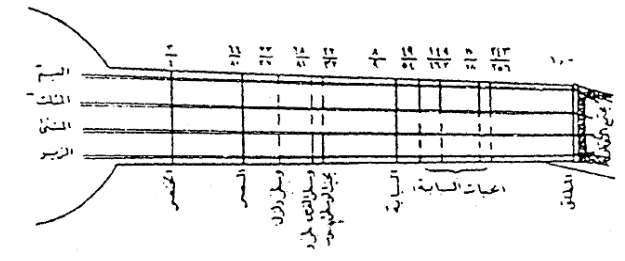

A)

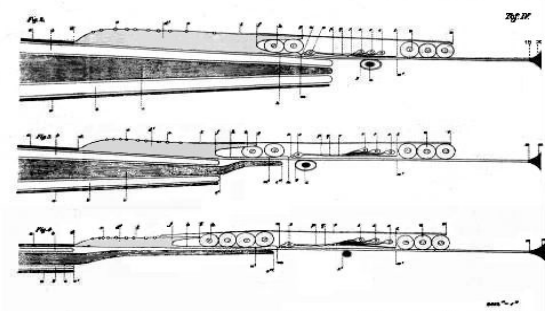

B)

Fig. 1-1. A) Early works in musical acoustics: the intervals of the natural music scale shown on the strings of a medieval Lute by Abu-Nasr Farabi (872-950 AD), reproduced image by Barkeshly (1975) from Farabi's book 'The Great Music', with permission from Council of Persian Culture and Art. B) Early works in physiological acoustics: A schematic of the organ of Corti by Alfonso Corti, from his paper Zeitschrift für wissenschaftliche Zoologie (1851), retrieved from Mammano and Nabili, (2014).

The psychological and physiological acoustics, which is the scope of this thesis, began as early as $16^{\text {th }}$ century when Galileo Galilei (1564-1642) wrote: "Waves are produced by the vibrations of a sonorous body, which propagates through the air, bringing to the tympanum of the ear a stimulus which the mind perceives as sound" (Clavelin, 1974). In 19 ${ }^{\text {th }}$ century, the Italian anatomist Aslfonso Corti (1822-1876) conducted microscopic research on at least 200 human and animal cochleae and discovered the sensory structures of the mammalian auditory system (Slepecky, 1996), which was later named after him as the organ of Corti.

Furthermore, Hermann Von Helmholtz (1821-1894) published his theory of resonance which hypothesized that the inner ear acts as a combination of independent resonators similar to tuning forks or a piano string (Slepecky, 1996).

Georg Von Bekesy (1899-1972) published his first paper on the pattern of vibration inside inner ear, in 1928 (Bekesy, 1928). Bekesy developed a method to assess biophysical properties of the cochlear structures in human cadaver temporal bones, using strobe 
photography. His measurements dismissed the Helmholtz theory of resonance and showed that the vibrations in the organ of Corti form a travelling wave propagating from the base to the apex (Bekesy, 1960). Moreover, Bekesy implemented a mechanical replica of the human cochlea to simulate the sound-induced vibrations. The results confirmed the key concept of frequency dispersion by the organ of Corti (so called 'tonotopy'), as was also predicted by Helmholtz resonators.

In 1978, otoacoustic emissions, generated by the cochlea in response to acoustic clicks, were recorded at the ear canal (Kemp, 1978). This phenomenon could not be explained by simple passive vibration. The recording of the OAEs led to the discovery of the active forces inside the cochlea. There have been numerous modeling attempts to quantitatively understand the active mechanisms in the mammalian inner ear. One of the significant works was done by Neely and Kim (1983) who introduced an active signal-transmission model of the cochlea in which the outer hair cells produce active motile forces that cancel the friction.

In the $21^{\text {st }}$ century, the classic image of the ear being the exclusive tool of the hearing sensation, has drastically changed and newer concepts such as genetics, attention, working memory, cognition and top-down processes have been added to the image (Smith et al., 2014; Rönnberg et al., 2013; Classon et al., 2013; Stenfelt and Rönnberg, 2009) . As a result, the hearing science today has become rather inter-disciplinary in the sense that biophysicists, engineers, physiologists, audiologists, neurologists and cognitive psychologists work together in a translational context to provide state of the art answers to the many existing questions within physiological and psychological acoustics.

\subsection{A Brief Introduction to Anatomy of Cochlea}

The mammalian inner ear is the innermost part of the auditory periphery inside a hallow cavity, known as the bony labyrinth, located in the temporal bone of the skull including a complex system of passages. The human inner ear consists of two major parts: 1) the vestibulum (vestibular system) which contributes to the sense of spatial orientation and balance and 2) the cochlea which is the auditory portion of the inner ear, the subject of this thesis.

The word cochlea is derived from the Greek word kokhlias meaning snail, spiral shell (Guthrie, 1978). It is a spiral-shaped cavity making 2.5 turns around its axis with a total length of $35 \mathrm{~mm}$, in an average adult human (Fettiplace and Hackney, 2006). The cochlea is partitioned into three liquid-filled chambers (scalae): scala vestibule (filled by perilymph), 
scala media (filled by endolymph) and scala tympani (filled by perilymph). The cochlea is linked to the middle ear via a membrane-covered opening, known as oval window, which is directly contracted by the stapes. The width of the cochlear duct is smaller near the stapes, however, it increases toward the apex.

\subsubsection{The lateral wall of the cochlea and the stria vascularis}

The lateral wall of the cochlea (spiral ligament) is a periosteum that forms the outer wall of the cochlea. It is attached to a vascularized tissue, known as the stria vascularis, which is believed to pump ionized potassium $\left(K^{+}\right)$into the endolymph of scala media (Slepecky, 1996). This is believed to directly contribute to the $89 \mathrm{mV}$ endocochlear potential (EP) in a healthy human cochlea. Moreover, the stria vascularis is the only tissue in human body where blood capillaries pass through two very thin layers of epithelial cells (Slepecky, 1996). Therefore, stria vascularis may be very sensitive to the quality of the blood circulation and the general metabolic status of the individual (Riquelme et al. 2013). It is explicitly investigated in this thesis (chapter 3 and papers II, III) how the age-related decline of the stria vascularis structures modifies the auditory functions.

\subsubsection{The organ of Corti}

The organ of auditory, the organ of Corti, is situated in scala media, in the core of the cochlea (Fettiplace and Hackney, 2006). The organ of Corti (Fig. 1-2) comprises various auditory sensory and supporting cells and rests on a stiff structural basis, basilar membrane (BM). For the organ of Corti, the stiffness of the cells progressively decreases from the base toward the apex whereas their mass, width and thickness increases from the base to the apex (Bekesy, 1960).

The Dieters cells, which belong to a stiff type of supporting cells with filaments, rest directly on the BM; they are closely associated with the outer hair cells (OHCs). The OHCs are long and cylindrical membranous cells that are capable of altering their length due to polarization (electromotility). There are averagely around $11000 \mathrm{OHC}$ in adult humans which are situated in 3 parallel rows (Slepecky, 1996). On the top of each OHC there are around 20 stereocilia (also known as hair bundles) that act as mechanosensing organelles by opening their mechanoelectrical channels leading to hyperpolarization of the OHC (Fettiplace and Hackney, 2006). The OHCs are held in place by an extracellular layer, known as reticular lamina (RL), which is mainly composed of collagenous fibers. 


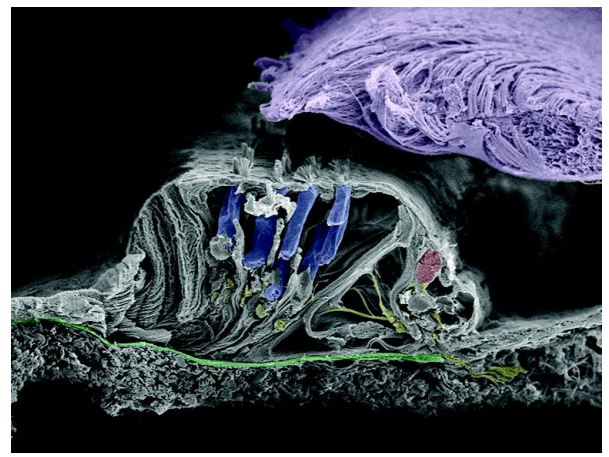

Fig. 1-2. A microscopic image of the organ of Corti depicting various cochlear structures. With permission from Kristian Pfaller, Helge Rask-Andersen, Anneliese Schrott-Fischer and Rudolf Glueckert.

The tips of the tallest OHC stereocilia are embedded in a gel-like structure, known as the tectorial membrane (TM). The stereocilia of the inner hair cells (IHCs) are also attached to the TM, on the other side (Slepecky, 1996). The TM is classically believed to act as an acoustic shear transformer to excite the IHC sterocillia. The IHCs are goblet-shaped cells that are enlarged in their nucleus regions at the basal end. There are around 4000 IHCs in an adult human cochlea forming a row along the organ of Corti. The IHCs are believed to play a primarily sensory role in the auditory periphery, since their basal ends synapse directly with the auditory nerve (AN) fibers.

\subsubsection{Innervation}

There is a rather complex network of both afferent (toward the brain) and efferent (from the brain toward the periphery) neural fibers running between the cochlea and the brainstem. The IHCs are capable of releasing neurotransmitters on the AN fibers via the IHC-AN synapse, converting the cochlear vibrations into neural spikes toward the brain cortices (Sumner et al., 2002). The AN fibers are often categorized by their spontaneous rate into: high spontaneous rate (HSR), medium spontaneous rate (MSR) and low spontaneous rate (LSR) fibers.

There are two types of olivocochlear efferent fibers: lateral efferents, which are connected to the IHCs, and medial efferents which form a cistern-shape synapse at the OHC terminals. This efferent network makes it possible for the central nervous system to manipulate the biomechanics of the cochlea in a 'top-down' manner (Stenfelt and Rönnberg, 2009). This is probably one of the front lines of the today's auditory modelling (section 6.2).

\subsection{Sensorineural Hearing Impairments and Inner-ear Pathologies}

The sensorineural hearing impairment refers to a range of hearing problems that take root from abnormalities within the inner ear (cochlear hearing loss), dysfunction of the auditory nervous network (neural hearing loss) or even impairment of the auditory processing centers 
of the brain (cortical hearing loss). Sensorineural hearing impairments are known to be caused by various congenital and acquired diseases such as rubella, infection, aplasia, meningitis, measles, vestibular schwanoma, Meniere's disease and some autoimmune diseases (Davis, 1989). It can also be caused by ototoxic drugs such as aminoglycosides and antimetabolites (Robertson et al., 2006). However, the majority of the sensorineural hearing impairments originate from cellular lesions and structural pathologies within the cochlea mainly due to aging (presbyacusis) and acoustic overstimulation (Davis and Moorjani, 2003); which are the main topic of this study.

\subsubsection{Epidemiology}

Hearing impairment is the most common sensory deficiency in humans (Davis, 1989) with drastic social and psychological consequences for the individuals as well as economic costs for the well-fare providers and governments. It is estimated that approximately $20 \%$ of adults suffer from some degrees of hearing impairment, globally (Davis and Moorjani, 2003).

The hearing impairment has a close correlation with aging. In the United Kingdom, for instance, only $3 \%$ of the population aged between 18 and 30 have an average hearing loss of more than $25 \mathrm{~dB}$ on 0.5, 1, 2 and $4 \mathrm{kHz}$, in the better ear (Davis, 1989). For the population aged 51-60 the prevalence of $25 \mathrm{~dB}$ hearing loss is approximately $20 \%$ which drastically increases for older population groups reaching $91 \%$ for the population aged over 80 years (Davis, 1989). As the life expectancy is notably increasing world-wide, the number of the older citizens and thus the prevalence of the age-related hearing loss would also increase significantly. Chapter 3 and papers II, III and V investigate the underlying causes of metabolic presbyacusis ('healthy aging') and study the manipulation of the auditory functions due to the aging of the cochlear lateral wall.

The hearing impairments due to damages caused by noisy working environments have been common in industrialized communities (Davis and Moorjani, 2003). Today fortunately, most employers and employees are aware of the work-related damages. Thus, well-designed hearing protections are widely used and more effective solutions are exploited to reduce the noise at work places (Kochkin, 2005). However, it is estimated that only in USA around 17\% of the adults aged 20-69 suffer from permanent damages to their hearing caused by excessive exposure to noise or acute acoustic trauma (Niskar et al., 2001). Chapter 4 and papers IV and $\mathrm{V}$ study the effects of the cochlear lesions due to acoustic over-stimulations on the auditory functions. 


\subsection{Auditory Modelling: Computational Models vs. Physiologically-based Models.}

Models have been exploited to sharpen our understanding of various mechanisms and systems. In principal, the auditory models can be traced back to the early Helmholtz 'tuning forks' theory (section 1. 2). A great portion of the modern models have been based on the auditory filters (Meddis et al., 2010). The auditory filter models are grounded on the to-someextent practical reasoning that the auditory system filters the sound signal and thus the characteristics of this system can be best described by filter banks.

For more than seven decades [since (Fletcher, 1940)], numerous auditory filter models have been divised to better runderstand the hearing-related issues and apply to various psychoacoustic measures of the human auditory system. These computational models classically exploit different combinations and types of filters such as gammatone and the gammachirps to imitate different stages of the auditory system [e.g. (Irino and Patterson, 2001)]. The recent auditory filter models are well capable of reproducing several key features of the auditory system such as critical bands, frequency selectivity, compression and frequency- and level-dependent amplitude responses [see (Meddis and Lopez-Poveda, 2010) for a review]. Furthermore, these computational models have been very feasible for being integrated within machine hearing-systems.

Even so, for these models the underlying strategy is to mimic the over-all psychoacoustic/behavioural outcomes by means of the computational elements (i.e, filter banks) without directly linking these outcomes with fundamental biophysical details and undergoing subprocesses at the cell level. In the last decade or so, the evolution of measurement techniques have led to experimental data on cell-level structural details and their corresponding mechanisms inside the inner ear (Cooper, 1998; de Boer and Nuttall, 2000; Rubles and Ruggero, 2001; Nowotny and Gummer, 2005; Ghaffari et al., 2007; Chen et al., 2011). Based on these explicit findings, new models have been developed to either explain functionality of specific parts of the mammalian cochlear system (Lopez-Poveda and Eustaquio-Martin, 2006; Liu and Neely, 2009) or to simulate the whole cochlear responses (Ramamoorthy et al., 2007; Saremi and Stenfelt, 2013). The major difference between these newer models and the classic filter models is that these newer models comprise more fundamental biophysical parameters such as electromechanical properties of the cochlear structures rather than solely computational filters. 
The physiologically-based model presented in this thesis belongs to this latter generation of auditory models. The input to the model is the sound-induced acoustical vibration of the stapes and the output of the model is the neural activity on the afferent AN. The current model is developed with the aim of simulating how specific inner ear pathologies modify the spectral and the temporal features of the cochlear responses. 



\section{THE MODEL}

\subsection{Overview}

This chapter introduces a physiologically-based simulation model of the human organ of Corti. The basic modeling concept here is based on the lumped-element principle and the model is devised in form of a signal-transmission line. The model incorporates passive vibrations; nonlinear transduction of the hair cells, the OHC's active force generation, as well as the TM, shearing and vibration to neural transmission at the IHC-AN synapse. The classic cochlear models often assume that cochlear structures are longitudinally de-coupled except for the energy propagation through the fluid, to obtain simplicity (Ghaffari et al., 2007). However, the longitudinal coupling along the cochlear structures has also been taken into account, in this work.

The cochlear processes, specifically the electromechanical transduction, are highly nonlinear and thus they can only be simulated in time-domain. This deprives the investigators from the analysis of the system in frequency domain. Therefore, the presented signal-transmission model is linearized using the small-signal method to form a frequency-domain linearized cochlear model. This enables us to simulate the spectral characteristics of the mammalian cochleae.

The simulation model has a large number of biophysical parameters which are listed in table I of paper III. The idea is to use physiologically-based parameters, in so far as known, since the aim is to simulate how the manipulation of a specific biological parameter, due to certain diseases/impairments, modifies the spectral and temporal features of the cochlear responses and, thereby, the entire auditory functionality. As there is lack of hard copy in vivo measurements inside the human inner ear (section 2.5), the corresponding parameter values from other mammalian cochleae have been extrapolated for the human, whenever necessary.

\subsection{Modelling Method}

Inside the SM lies the organ of Corti which is sandwiched between two cellular matrices, the BM and the TM (Nam and Fettiplace, 2010). An airborne sound pressure field is transmitted via the outer and middle ear to the inner ear. It causes the stapes to vibrate resulting in a travelling wave along the organ of Corti propagating from the base towards the apex (Bekesy, 1960). The displacement of the BM due to this travelling wave triggers some active processes, associated with the OHCs, which act fast enough to be in synchrony with the 
incoming sounds. The force generated by these active processes is fed back to the transmission line which, in turn, boosts the vibration pattern of the travelling wave.

To model these passive and active electromechanical interactions, the lumped element modelling principle has been used as the main modelling approach, in this work. The lumped element method simplifies the behavior of spatially distributed systems into a series of discrete entities each of which approximates the behavior of the system in specific regions, under certain assumptions (Caloz and Itoh, 2005). These discrete entities can then be connected together to describe the entire system. The lumped-element models are widely used in electrical and mechanical engineering, as well as in acoustics. The lumped element modelling is a valid method as long as the length of the partitions is well below the sound wave length (Caloz and Itoh, 2005).
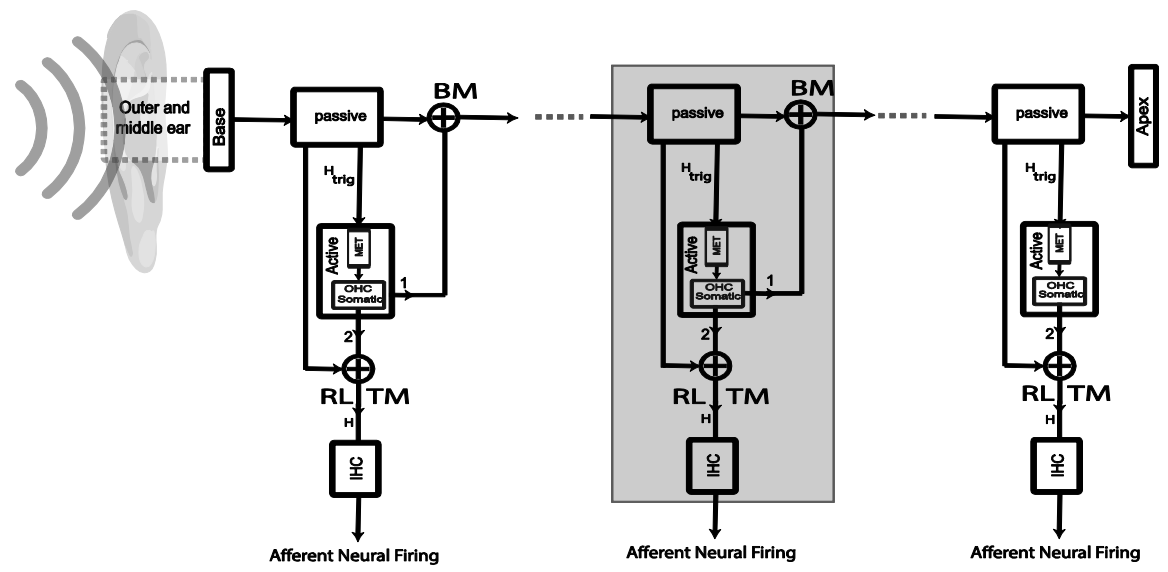

Fig. 2-1. A schematic of the model consisting of $\mathrm{N}$ branches (cochlear partitions) extending from the base to the apex. Each partition consists of passive elements (BM, RL and TM) as well as an active force generator (OHC). The generated active force is fed-forward to BM and RL via path 1 and 2, respectively.

According to the lumped element modeling principles, the organ of Corti is assumed to consist of $N$ partitions along the cochlear duct extending from the base (on the left) to the apex (on the right), as depicted schematically in Fig. 2-1. Each branch of the system indicates a single cochlear partition consisting of passive block and an active block (OHC) together with the IHC block. The forces generated by the active block are fed-forward to the BM and the RL through two paths. The IHC block represents the neural conversion which occurs at the IHC-AN synapse. The input to the model is the vibration induced by the stapes and the 
output is the neurotransmitter release on the auditory nerve by each partition. The number of partitions can be arbitrary set, although in this thesis 100 partitions $(\mathrm{N}=100)$ are used.

Figure 2-2 depicts the components inside a single cochlear partition: BM, RL and TM. The $\mathrm{OHCs}$ are suspended between the RL and the BM; and the OHC motile forces (depicted by $f_{O H C}$ in Fig. 1) are represented by a pair of forces inside the organ of Corti which on a cycleto-cycle basis alternately pull the RL and the BM (via Dieters cells) together and push them apart. For simplicity, the Dieters supporting cells have been considered as incompressible masses here.

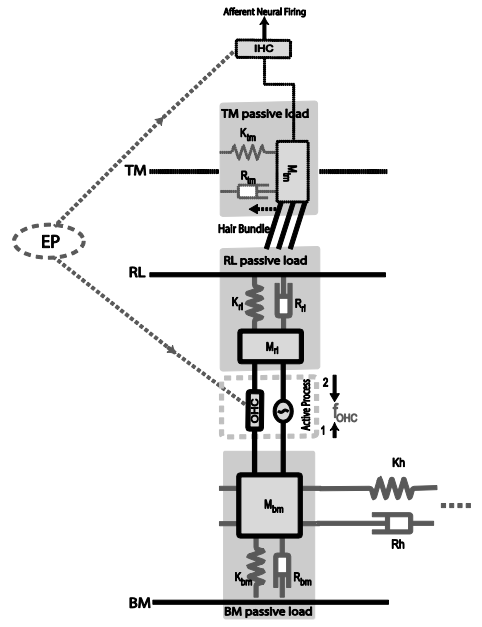

Fig. 2-2. A cochlear partition along the cochlear duct. It comprises three passive loads: the BM, the RL and the TM. The OHC is the active element which acts between the RL and the BM by applying a motile force (denoted by $f_{O H C}$ ) pulling them together and thereby boosting the vibration. This additive behavior is included in the model by means of two feed-forwards both on the BM and the RL. The boosted vibration is transmitted to the IHC via the RL-TM shearing. The longitudinal coupling along the cochlear structures is modeled by a damper $(R h)$ and a spring $(K h)$. The EP block is depicted by dotted lines; it controls the OHCs and IHCs by providing them with necessary flow of $K^{+}$ions.

\subsection{Passive Components}

In order to explain the vibrations, each passive mechanical load is modeled by a viscous 'mass-spring-damper' combination. Thus, the BM is represented by its mass $\left(M b_{i}\right)$, its stiffness $\left(K b_{i}\right)$ and its damping coefficient $\left(R b_{i}\right)$. Similarly, RL and TM are modeled by $\left(M r_{i}\right.$ , $\left.K r_{i}, R r_{i}\right)$ and $\left(M t_{i}, K t_{i}, R t_{i}\right)$, respectively. Here, only the shearing impedance of the TM is included and the bending impendence has been neglected.

\subsubsection{The longitudinal coupling along the cochlear structures and the loading effect}

Cochlear models typically assume that BM is longitudinally uncoupled (Ghaffari et al., 2007). Mathematically, the decoupled BM is very attractive to modelers; it allows the equations that describe the motion of a single partition to be independent of the equations that describe the motion of other adjacent partitions along the cochlear duct. However, Naidu and Mountain (2001) have quantified longitudinal coupling along the BM of gerbils. Besides, Meaud and Grosh (2010) have also introduced a 3-dimensional model of the cochlea. They 
simulated the effect of TM longitudinal coupling on the cochlear response and demonstrated that structural longitudinal coupling is non-negligible.

In the current model, the longitudinal coupling along the organ of Corti is modeled by springs and dampers between the cochlear partitions along the transmission line $\left(K h_{i}, R h_{i}\right.$ in Fig. 1). This approach is very similar to the one-dimensional model of [Naidu and Mountain (2001), Fig. 7], except that, here the longitudinal damping $\left(R h_{i}\right)$ is also included. Figure 2 in paper I depicts the circuit model for the longitudinal coupling between the passive structures. Figure 3 of paper I illustrated the electrical analogy for the passive mechanical system. As explained by Eq. (1) and (2) of paper I, the system is solved so that the partitions give characteristic frequencies similar to those measured in cadaver passive human cochleae [shown in Bekesy (1960), Fig. 11-43].

\subsection{Active Mechanisms}

To explicitly investigate the active force generation process inside the cochlea a three-stage system is devised (Fig.3 in paper III). The corresponding sub-processes are: 1) The Stria vascularis: the biological battery. 2) The mechanoelectrical transduction (MET): the driver of the OHC's molecular motor. 3) The somatic motility: the OHC's molecular motor.

\subsection{1. stria vascularis: the biological power supply of the Cochlea}

As described in section 1.3.1, stria vascularis pumps $K^{+}$ions into scala media. The influx of the electrically-charged $k^{+}$ions contributes directly to the existing $89 \mathrm{mV}$ electrical difference $(\mathrm{EP}=89 \mathrm{mV})$ along the human cochlear duct (Slepecky, 1996). This biological battery supports the cochlear system by providing the MET channels of both the OHCs and the IHCs with the necessary electrical current. Thus, the EP is illustrated as a controller of the OHC and the IHC blocks as shown in Fig.1 of paper III.

The stria vascularis as a vascularized cellular body can be represented by a resistance, $R_{s t}$. The electromechanical gradients driving the flow of the $k^{+}$ions into the SM is represented by an ideal voltage source (battery), EP, and the fluid resistance inside the SM is denoted by $R_{s m}$, as shown in Fig. 3 of paper III.

\subsubsection{Mechanoelectrical transduction: the driver of the somatic motor.}

The MET channels are opened by the so called 'gating springs', which are stretched when the tips of the $\mathrm{OHC}$ stereocilia (the $\mathrm{OHC}$ hair bundle) are deflected due to the incoming sound- 
induced displacements of the BM (Fettiplace and Hackney, 2006). The opening of the MET channels leads to the influx of $\mathrm{Ca}^{2+}$ ions which induces a receptor current $\left(i_{r}\right)$.

This receptor current $\left(i_{r}\right)$ has been measured in different mammalian cochleae as function of the hair bundle displacement (Fettiplace and Hackney, 2006). A peak current is seen almost immediately after the channels have been opened (fast adaption). The MET channels then reclose slowly and the receptor current adapts with a specific time constant (slow adaption) to a non-zero residual level $\left(I_{\text {rest }}\right)$. This process can be seen in the recordings shown by [(Kros, 1996), Fig. 6.3 (A)] which depict the adaption of receptor currents in mouse cochleae.

Therefore, the receptor current $\left[\left(i_{r}(t)\right]\right.$ can be written as the combination of the peak current $\left(I_{r}\right)$ and a time-dependent transient current $\left[\hat{i}_{r}^{m}(t)\right]$ which corresponds to the decaying slow adaption as stated by Eq. (2-1) below.

$$
i_{r}(t)=I_{r}+i_{r}^{m}(t)
$$

This peak current $\left(I_{r}\right)$ can be estimated as a function of the hair bundle displacement by a second-order Boltzmann function (Eq. (2) of paper IV) resulting in the MET curve illustrated in Fig. 2 of paper IV. This curve demonstrates a highly non-linear function; nonlinear systems can only be simulated in time domain. However, here we exploit the small-signal linearization approach to obtain a linear estimate of the MET mechanism around certain operating points. Thus, the peak current $\left(I_{r}\right)$ can be stated by Eq. (2-2) where $x_{r l}$ denotes the displacement of the RL (which is assumed to correspond to the displacement of the hair bundle) and $\alpha_{d}$ is the slope of the MET curve at a specific operating point. Equation (2-2) is only valid as long as the displacement of the hair bundle is reasonably small around the operating point, according to the small-signal principles.

$$
I_{r}=\alpha_{d} \cdot x_{r l}
$$

The time-dependent decaying transient current $\left[\tilde{i}_{r}(t)\right]$, however, can be thought of a lowpass filter to the velocity impulse (Liu and Neely, 2010). Thus, it can be written according to Eq. (2-3) where $\frac{d x_{r l}}{d t}$ is the RL velocity and $\alpha_{v}$ denotes a velocity-to-current coefficient corresponding to MET's sensitivity to RL velocity.

$\tilde{i}_{r}(t)=\alpha_{v} \cdot\left(\frac{d x_{r l}}{d t}\right)$ 
Inserting Eq. (2-2) and Eq. (2-3) in Eq. (2-1) leads to the following differential equation which takes into account both the peak current and the transient current induced by the MET process, based on small-signal linearization.

$i_{r}(t)=\alpha_{d} \cdot x_{r l}+\alpha_{v} \cdot\left(\frac{d x_{r l}}{d t}\right)$

A first order linear time-invariant (LTI) system is governed by the following equation where $\tau$ is the time constant of the system. The time constant is an important feature of the electromechanical systems that represents the time it takes for the response to decay to 0.37 of its initial value.

$i_{r}(t)=\frac{1}{\tau} x_{r l}+\left(\frac{d x_{r l}}{d t}\right)$

Eq. (2-4) can be re-written as following.

$\frac{i_{r}(t)}{\alpha_{v}}=\frac{\alpha_{v}}{\alpha_{v}} \cdot x_{r l}+\left(\frac{d x_{r l}}{d t}\right)$

Comparing Eq. (2-6) with Eq (2-5) indicates that the time constant for the receptor current $i_{r}(t)$ induced by the MET mechanism has the time constant below.

$\tau=\frac{\alpha_{v}}{\alpha_{d}}$

This time constant shows how fast the MET channels reclose. The time constant has been measured to be 123 us in guinea pig cochlea (Fettiplace et al., 2005). However, Liu and Neely (2010) suggested that this time constant must be at least ten times higher in human MET.

\subsubsection{The somatic motility: the OHC's molecular motor for generating active forces.}

The OHC's membranous body has a conductance $(G)$ and capacitance $(C)$ (Liu and Neely, 2009). Accordingly, the receptor current $\left(i_{r}\right)$ resulting from the MET mechanism, described above by Eq. (2-1) to (2-7), induces a receptor voltage $\left(V_{r}\right)$. The somatic motor is believed to be driven by this receptor voltage (Kros, 1996). It has been experimentally observed that individual $\mathrm{OHCs}$, dissociated from the cochlea and electrically stimulated, shorten in response to this receptor voltage (Fettiplace and Hackney, 2006). Because of the speed of the mechanical response these cells can theoretically alter their length and shape in synchrony with the acoustical stimulus for the frequencies spanning the whole auditory range, pulling 
and pushing the RL and the BM and thereby pumping energy into the transmission line of Fig. 2-1.

We used the piezoelectric model proposed by Liu and Neely (2009) to calculate the transfer function [see paper III, Eq. (7)] to relate OHC contraction with the RL displacement. This transfer function is considered the open-loop displacement gain produced by the OHC. As shown by Eq. (7) of paper III, this gain is directly proportional to the slope of the MET curve $\left(\alpha_{d}\right)$ (the slope of Fig. 2$)$ as well as the MET's velocity sensing component $\left(\alpha_{v}\right)$ which is determined by the time constant corresponding to the re-closure of the MET channels (see Eq. 2-7 above).

The OHC transfer function is integrated into the transmission line by a pair of positive feedforwards both on the BM and on the RL as seen in Fig. 2-1. The frequency response of the entire partition (denoted by $H$ ) is calculated according to Eq. (9) and (10) of paper III; these equations take into account the structural coupling along the cochlear duct and the associated loading effect.

\subsection{Parameters of the Model}

The human inner-ear is deeply covered by the petrous bones in a rather inaccessible part of the skull. As a result, although some passive biophysical measures of the human cochleae are known thank to measurements on cadaver temporal bones (Bekesy, 1960; Stenfelt et al., 2003), in vivo measurements inside human cochleae are currently impossible. Fortunately, recordings from mammalian cochleae especially gerbil and guinea-pig are to some extent available (Cooper, 1998; de Boer and Nuttall, 2000; Rubles and Ruggero, 2001; Nowotny and Gummer, 2005; Ghaffari et al., 2007; Chen et al., 2011).

As depicted in Fig. 2-2, each single cochlear partition acquires 31 biophysical parameters. The goal here is to use biologically-based parameters, in so far as known, so that the effect of manipulations in certain parameters (due to specific pathologies) on the entire auditory system can be explicitly simulated. To obtain the passive parameters (i.e. BM mass, OHC body stiffness, etc.) the measurements from the cadaver structures were used. For instance, the width of the cochlear duct was reported by Liu and Neely (2010) at the base, in the middle and at the apex of the cochlea. These values were linearly interpolated to give us the corresponding values for the in-between partitions. 
Whenever there were no human data available (which is the most likely case with active parameters), the corresponding recordings from other mammalians were extrapolated to give reasonable values for the human counterpart parameter. The precision and the validity of such 'translations' from the animal data into the human data will be always under question as long as the hard copy human measurements are not entirely available. Table I of paper III describes all parameters of the model as well as the sources.

\subsection{Model Predictions vs. the Animal Data}

Cooper (1998) measured the BM mechanical responses to pure tone stimuli at the basal turn of the guinea pig cochlea at $3 \mathrm{~mm}$ from the base $(\mathrm{CF}=17 \mathrm{kHz})$ using a displacement-sensitive laser interferometer. de Boer and Nuttall (2000) also recorded data on velocity of the BM at the same location of the cochlea using a laser velocimeter [(de Boer and Nuttall, 2000), Fig. 1]. With this technique they obtained frequency response of the BM velocity ratio with respect to stapes (BM velocity divided by stapes velocity) for stimulation levels of $60,70,80,90 \mathrm{~dB}$ SPL.

In order to compare animal data with the model predictions, the corresponding parameters of the human model (listed in tables I to III in appendix A) were modified to those of the guinea pig cochlea presented in [Ramamoorthy et al. (2007), table I, II]. The modified guinea pig model was used for simulating the BM velocity ratios at the sharpest point of the MET curve where the somatic motor functions maximally. This point corresponds approximately to the experimental data at a relatively low stimulation level (20 dB SPL) which also gives the highest amplification and sensitivity. The Cooper (1998) and the de Boer and Nuttall (2000) data (for the stimulation level of $20 \mathrm{~dB}$ SPL) were normalized and averaged. The result was shown versus the prediction of the model in Fig, 7 of paper III. 


\section{BIOPHYSICS OF THE AGING COCHLEA}

\subsection{Overview}

Aging in humans refers to accumulation of biological, psychological and social changes in an individual over time (Stuart-Hamilton, 2006). One common and tangible consequence of aging is often the decline of hearing. The age-related hearing loss (ARHL), or presbyacusis, is one of the most widespread chronic health problems among older citizens; as more than one third of individuals over 65 years old are believed to suffer from prominent hearing difficulties (Gordon-Salant and Fristina, 2010). An important issue which is discussed in the beginning of the chapter addresses the question: what is 'purely' age-related and what is not? This is particularly important because acquired insults to the cochlea (due to noise exposure, drugs, etc.) are sometimes mixed up with age-related manipulations.

\subsection{How Does Aging Manipulate the Cochlear System?}

Schunknecht (1974) categorized human presbyacusis into four types: 1) mechanical, where the organ of Corti stiffens, 2) neural, which refers to loss of neuronal cells, 3) sensory, referring to age-related death of sensory hair cells and 4) metabolic, which refers to the degeneration of the cochlear lateral wall leading to the decline of the cochlear power supply (reduction of EP).

To date, no direct evidence of age-related stiffening of cochlear structures have been reported. Thus, the mechanical presbyacusis has been dismissed by many investigators (Schmiedt et al., 2002; Lang et al., 2010). Moreover, Schmiedt et al. (2010) suggested that the diagnoses of the 'mechanical presbyacusis' which was derived from a flat 30-40 dB HL loss may actually be linked to severe cases of metabolic presbyacusis rather than the 'mechanical presbyacusis'. Neural presbyacusis, however, is one of the main contributors to the ARHL as the shrinkage and loss of the AN fibers and the spiral ganglion cells due to aging is very common (Makary et al., 2011). Kujawa and Liberman (2009) showed that a human averagely looses 100 neural ganglion cells per year of age. The AN lies outside the cochlea, however, paper III briefly investigates how age-related neuaral degeneration can contribute to the decline of the temporal resolution.

The loss of the hair cells with aging in mammalian cochleae has been reported (Mcfadden $e t$ al., 1999; Kros, 1996). Expectedly, there is a higher number of missing hair cells in an aged cochlea in comparison with the young one (Bettacharyya and Dayal, 1989). However, the 
question is if these hair cell losses have been due to pure aging or due to the exposure of the ear to acoustic overstimulation, as most humans (as well as animals) have been exposed to degrees of destructive noise. Schmiedt et al. (2010) and Mills et al. (2006) showed that the hair cell loss is not significant in quiet-aged gerbil, gerbils who have spent all their lives in sound-proof cages without being exposed to any sound. They concluded that the cochlear ARHL is more of strial origin (metabolic presbyacusis) rather than of a sensory nature.

\subsection{Structural Degeneration of the Stria Vascularis}

\subsubsection{Age-related strial decline}

Stria vascularis, located in the lateral wall of the cochlea, is surrounded by blood capillaries (Slepecky, 1996). It comprises mostly fibrocyte fibers and consists of three different cell types: marginal, intermediate and basal. The marginal cells are dark in color and form a layer of cell coat having direct contact to the endolymph. These cells are characterized with high rate of metabolism and ion $\left(\mathrm{K}^{+}\right)$secretory function (Trowe et al., 2011). The intermediate cells, which are relatively clear in color, form a discontinuous layer below the marginal cells while the basal cells, darker in color, are directly attached to the lateral wall of the cochlea (Fettiplace and Hackney, 2006).

Trowe et al., (2011) showed that the trans-membrane protein Cadherin (calcium-dependent adhesion) has a key role in maintaining the structural integrity of the stria vascularis by studying the E-cadherin mutant mice. Their results indicate that the age-related reduction of the E-cadherin interferes with the architectural maintenance of the fibrocystic marginal cells which impairs their interaction with other stiral cells (intermediate and basal). Consequently, the functionality of the stria vascularis in pumping the influx of $K^{+}$into the endolymph and maintaining the optimum $\mathrm{EP}$ ( $89 \mathrm{mV}$ in humans) is impaired. This leads to the reduction of the EP such that there is a decrease in the power supply of the cochlear system, a medical condition known as metabolic presbyacusis.

\subsubsection{Effects of metabolic disorders on the structural integrity of stria vascularis}

Since the stria vascularis is the only known epithelial tissue where the blood capillaries pass through its cellular layer, the structural integrity of its cells may be very sensitive to the quality of the blood and the metabolic status of the individual. Therefore, it is totally reasonable that metabolic disorders and cardiovascular diseases manipulate the strial cells (Davis and Moorjani, 2003; Riquelme et al., 2012). 
The effects of metabolic disorders caused by specific health conditions such as syndrome $\mathrm{X}$ (metabolic syndrome), diabetes and cardiovascular diseases on structural integrity and the functionality of the strial cells have not yet been thoroughly investigated. However, Fukushima et al. (2006) investigated temporal bones of 18 diabetic cadaver humans in comparison with a group of non-diabetic temporal bones to morphometrically study the effects of diabetes on the cochlear structures. The results indicated significant thickening and atrophy of the stria vascularis cells almost in all cochlear turns of the diabetic specimen.

Moreover, Riquelme et al. (2012) studied the effect of lacking an insulin-related peptide, insulin-like growth factor 1 (IGF-1), on the wild mice strial cells. IGF-1 is a hormone that plays an important role in metabolic processes and its abnormality has a high correlation with various metabolic disorders, such as diabetes (Davis and Moorjani, 2003). Riquelme et al. (2012) showed that the IGF-1 deficiency affects the stria vascularis reminiscent of prematurely aged strial phenotype.

\subsection{Changes in Cochlear Responses due to Metabolic Presbyacusis}

To simulate the effect of metabolic presbyacusis on the cochlear responses, the physiologically-based model presented in chapter 2 and papers II and III is exploited. The EP is regarded as the variable whereas other parameters are assumed to remain constant. This is consistent with the metabolic presbyacusis concept whereby stria vascularis is impaired due to age-related metabolic degenerations while the $\mathrm{OHCs}$ and all other structures are assumed to remain healthy and intact.

\subsubsection{Effects of metabolic presbyacusis on the cochlear amplifier}

The frequency-domain electromechanical system, presented in chapter 2, is solved for 100 partitions $(\mathrm{N}=100)$ in MATLAB; the simulation results are valid for low intensity sounds according to the small-signal linearization principles. The idea is to compare the cochlear amplification when the EP is optimal in comparison with when the EP is reduced to half of its optimal value. Figure 8(a) of paper III depicts the decline in the magnitude of the cochlear frequency response due to the reduction of the EP, at $30 \%$ of the cochlear length from the base (basal region) whereas Fig. 8(b) shows the decline at a more apical region $(70 \%$ of the cochlear length from the base). These figures also demonstrate flattening of the frequency response due to the EP reduction which indicates the decline of the frequency sensitivity. 
The decline of the frequency response is much higher in the basal region [Fig. 8(a) of paper III], which is tuned to higher frequencies, than in the apical region [Fig. 8(b) of paper III], tuned to low frequencies. Figure 10(a) of paper III summarizes the decline in the magnitude of the cochlear frequency response along the cochlear duct as a function of the characteristic frequency. The result demonstrates a small loss followed by a sloping loss at frequencies higher than $1 \mathrm{kHz}$ which indicates the high-frequency profile of presbyacusis as well as changes in position-frequency (tuning pattern) of the cochlea.

\subsubsection{Effects of metabolic presbyacusis on the temporal coding of the coclea}

The BM vibrations are converted into the release of neurotransmitter by the IHC/AN synapse on the auditory fibers. Similar to the OHC MET channels, the EP also controls the IHC MET channels as well. The opening of the IHC MET channels results in a receptor current which hyperpolarizes the IHC body leading to $\mathrm{Ca}^{2+}$ build up at the IHC-AN synapse. Sumner et al., (2002) showed that the firing rate of the afferent auditory nerve is proportional to the cube of the $C a^{2+}$ build up [Eq. (11) and (12) in paper III].

As the EP is reduced due to metabolic presbyacusis, the IHC MET mechanism produces less receptor current which results in reduction of the $\mathrm{Ca}^{2+}$ build-up and eventually the inhibition of the AN firing rate. The exact timing of the auditory nerve activations is determined by the neurotransmitter firing rate. Therefore, the transmitter release rate has a great impact on the temporal coding features of the auditory signal such as phase locking (Lopez-poveda and Barrios, 2013). The decrease of the neurotransmitter firing rate implies a longer time interval and less accurate timing between the firings which, at least partly, may explain the decline of temporal resolution, the ability to follow rapid acoustic changes over time, as well as impaired phase locking in the aging auditory system (Pichora-Fuller et al., 2006; Anderson et al., 2012).

\subsubsection{Effects of metabolic presbyacusis on the tuning pattern of the cochlea}

Figure 8 (right) in paper III indicates that the position-frequency map (tuning pattern) of the cochlea is modified as the active processes decline due to presbyacusis. The results indicate that the characteristic frequencies of the cochlear partitions decrease as a function of the EP reduction. This is consistent with the simulations by Ramamoorthy et al. (2007) where they show a backward shift of the characteristic frequencies as the activity level of the OHCs decreases to $90 \%, 75 \%, 50 \%$ and $0 \%$. Besides, Lopez-poveda et al. (2007) clinically assessed the psychoacoustical tuning curves in three normal-hearing subjects. Their results suggested 
that at high-level intensities (where the cochlear amplification is low) the characteristic frequencies decreased both in basal and apical areas of the cochlea.

\subsection{Model Predictions vs. the Animal Data}

Schmiedt et al. (2002) measured the CAP (compound action potential) threshold elevations in gerbils with reduced EP at frequencies from 0.5 to $10 \mathrm{kHz}$. Schmiedt et al. (2002) measured the CAP thresholds in a group of quiet-aged gerbils whose EP values were reduced to 67, 55, 48, 43, and $17 \mathrm{mV}$ primarily due to age-related decline of the stria vascularis. In addition, they recorded the CAP thresholds in a group of young but furosemide-treated gerbil cochleae. Furosemide is a loop diuretic ototoxic medicine which reduced the EP by disrupting the stria vascularis functionality. The advantage of using furosemide is that it provides a fast and specified experimental model of metabolic presbyacusis in young cochleae where other structures are intact and healthy, unlike in the old cochleae. Furthermore, Schmiedt et al. (2002) also measured the CAP thresholds in a reference group of young and healthy gerbils.

The CAP threshold elevations were calculated according to the experimental data [Schmiedt et al., (2002), Fig. 7] for three cases ( $\mathrm{EP}=46 \mathrm{mV}, 48 \mathrm{mV}$ and $57 \mathrm{mV})$ and were shown together with the model prediction in Fig. 10(a) of paper III. For all the cases, the loss is small (around $10 \mathrm{~dB} \mathrm{HL}$ ) and constant at low frequencies followed by a sloping loss at frequencies over $4 \mathrm{kHz}$. The CAP thresholds of the furosemide-treated gerbils $(\mathrm{EP}=46 \mathrm{mV})$ demonstrated the closest match with the model prediction. 



\section{BIOPHYSICS OF THE NOISE-DAMAGED COCHLEA}

\subsection{Overview}

The destructive effects of acute acoustic trauma (e.g. in wars) or persisting noise (e.g. in noisy working environments) on one's hearing, is well known in modern societies (Kochkin, 2005). In spite of technical developments in noise control systems and production of better hearing protectors, there are still over 35 million employees only in Europe who are exposed to detrimental noise levels at work, on a daily basis (Sulkowski et al. 2004).

\subsection{How Does Acoustic Overstimulation Manipulate the Cochlear System?}

It has been demonstrated that stereocilia micromechanics is modified immediately after the exposure to overstimulation (Saunders et al., 1986). These biomechanical changes may recover shortly after the stimulation is ended (Pyykkö et al., 2003). However, if the stimulation is too intense or the duration of the noise exposure is too long, it may lead to permanent damage or even death of the outer hair cell (OHC) through either apoptosis or necrosis (Bohne et al., 2007).

There are different steps leading from acoustical overstimulation to the cellular lesion. These steps are either of metabolic or mechanical nature. The acoustic overstimulation can trigger several metabolic processes (such as oxidative pressure, modification of the cochlear blood flow causing local ischaemia, and synaptic hyperactivity) which eventually result in disrupted cochlear homeostasis (Bohne et al., 2007; Pyykkö et al., 2003; Robertson et al., 2006). Besides, the sound-induced overstimulation can also mechanically disturb the integrity of the cochlear structures leading to disorganization of stereocilia and rupture of the cell membranes (Bohne et al., 2007)

The metabolic/mechanical changes induced by the acoustic overstimulation can be timedependent in the sense that the changes may be reversible (Patuzzi and Moleirinho, 1998). However, if the overstimulation is severe enough, the associated metabolic/mechanical changes can lead to the death of the sensory cells which is believed to be rather irreversible (Robertson et al., 2006).

The cellular death occurs through either of the two processes: necrosis or apoptosis. Apoptosis is regarded as the programmed cellular death in the sense that a chain of morphological events occur serially: the cell's cytoskeleton breaks up, body shrinkage, 
nuclear rupture and finally DNA fragmentation (Bohne et al., 2007). In contrast to apoptosis, necrosis is a premature, anarchistic form of the cellular death that results from acute cell injury caused by external factors such as trauma, infection and toxin (Proskuryakov et al. 2003). During necrosis, the cell dies of autolysis (self-destruction) whereby the cell is destructed by the actions of its own enzymes (Pyykkö et al., 2003).

\subsection{Effects of Noise-induced Lesions on the Cochlear Amplifier}

The physiologically-based model presented in chapter 2 is exploited to simulate the effects of the OHC impairments due to overstimulation on the cochlear amplifications. However, the death of the sensory hair cells in the inner ear is not limited to the OHCs but includes death of the IHCs as well (Fu-Quan et al., 2012). Such IHC dysfunction can cause further decrease of the dynamic range as well as a reduction in the firing rate of the IHC-AN synapse which can lead to impaired intensity coding (Kurt et al., 2012) and, eventually, further audiometric loss. The noise-induced IHC impairments and neural degeneration (Kujawa and Liberman, 2009; Makary, et al., 2011) have not currently been included in this work. In other words, the focus has been on simulating the effects of the noise-induced OHC dysfunction on the magnitude of the cochlear amplifier.

To simulate the effects of the cochlear lesions, caused by acoustic overstimulation, on the cochlear amplifier, two major scenarios are studied here. Firstly, the sound-induced impairment of the $\mathrm{OHC}$ stereocilia and the corresponding 'gating spring' on the cochlear amplifications is investigated whereby the MET mechanism is altered due to these manipulations. Secondly, it is assumed that the traumatic overstimulation has been severe/long enough to directly damage the OHCs in specific regions of the cochlear duct.

\subsubsection{Effects of MET deficiency on the cochlear amplifier}

Previous studies have demonstrated that stereocilia micromechanics alters as a result of the exposure to intense stimulation (Saunders et al., 1986). These changes were associated with the loosening of the 'gating spring'. This implies that the MET channels open more easily in comparison with an intact MET channel. As described in section (2.4.2), the peak receptor current induced by the opening of the MET channels can be stated as a function of the stereocilia displacement according to Eq. (4-1) below where the sensitivity of the MET channels is defined by parameters $S 1$ and $S 2$. Furthermore, $P 1$ and $P 2$ are two constants which set the position of the MET curve along the $x_{r}$ axis. 
$I_{r}=\frac{I_{\max }}{\left(1+e^{S 2\left(P 2-x_{r}\right)}\right)\left(1+e^{S 1\left(P 1-x_{r}\right)}\right)}$

Patuzzi and Moleirinho (1998) monitored the changes in the biomechanics of the MET channels and the corresponding parameters in guinea pig cochleae due to various disturbances including acoustic overstimulation. As suggested by their experimental data, one may assume that due to the noise-induced loosening of the MET channels, the channels move faster from the close state to the open state which can be simulated by increasing the values of $S 1, S 2$ and $P 1$ in Eq. (4-1) above. The impact of these parametric changes on the MET curve is depicted in Fig. 3(a) of paper IV.

As Eq. (7) of paper III states, the magnitude of the active motile forces generated by the OHC somatic motor is directly proportional to the slope (first derivative) of the MET curve. Thus, the amount of the cochlear amplification is very sensitive to the shape of the MET curve. Figure 3(b) of paper IV shows the magnitude of the cochlear frequency response to lowintensity stimuli at $50 \%$ of the cochlear length from the base for the two cases in Fig. 3(a): the intact MET versus the traumatized MET; it depicts a $17 \mathrm{~dB}$ peak-to-peak attenuation. The data shown in Fig. 3 of paper IV is only valid at low-sound intensities near threshold, according to the small-signal linearization principles. It is interesting to investigate the magnitude of the frequency response at other sound intensities since the cochlear amplification is believed to decrease as the input sound intensity increases, in a compressive manner. Figure 4(a) of paper IV shows the peaks of the cochlear frequency response (magnitude) as a function of the input sound intensity for the two conditions: the intact MET vs. the traumatized MET.

The human perception of loudness is complex and is determined by various parameters (Moore, 2003) rather than solely the cochlear nonlinearity. Paper IV, however, suggests a mathematical relation between the loudness and the cochlear amplifications such that the loudness function could be estimated by integrating the cochlear gain with respect to the sound intensity; the results are normalized and shown versus an experimentally-based power function (Stevens, 1955) in Fig 4(b) of paper IV.

Figure 4(b) of paper IV indicates that for the traumatized MET (dashed line), the loudness perception starts at 0.5 [sones] in response to a sound intensity of $9 \mathrm{~dB}$. This indicates a 9-dB elevation in the hearing threshold in comparison with the solid curve. The dashed curve also grows more rapidly than the solid curve as the sound intensity increases and results in slightly 
higher loudness sensation for intensities between 20 and $45 \mathrm{~dB}$ SPL. This is reminiscent of the "loudness recruitment" whereby excessive loudness growth is felt by sensorineural hearing-impaired listeners (Moore, 2003). Both curves, however, approach a similar linear growth at higher intensities.

\subsubsection{Effects of the damages to the OHCs on the cochlear amplifier}

The damage to the OHCs can be extensive or limited to specific regions in the cochlear duct; this is determined by the frequency content of the destructive stimuli (Moore, 2003). To simulate the effect of regional death of the OHCs, it was assumed that the OHCs were completely dead at the middle of the cochlea along an area corresponding to $5 \%$ of the total cochlear length. The magnitude of the active force generated by the OHCs [Eq. (7) in paper III] was set zero for the partitions lying in this dead region whereas other parameters of the model were intact. The results [Fig. 6 in paper IV] demonstrated a clear dip at frequencies corresponding to the dead region. The cochlear amplification at frequencies higher than the dead region remained intact. However, the cochlear amplification at lower frequencies, which correspond to locations proceeding the dead region, is slightly decreased.

The condition depicted in Fig. 6 of paper IV is for narrow-band stimulus. The frequency band of the destructive stimuli can be broader; thus the hair cell death may not always be aggregated in a narrow region forming a pure 'dead region' such as in Fig. 6, paper IV. Also, unless the overstimulation is too severe, the damaged region can consist of a mixture of dead and intact $\mathrm{OHCs}$ with different ratios.

The configuration shown in Fig. 7(a) of paper IV depicts a simplified scenario whereby the cochlear length is divided to 3 equal regions. The OHCs are assumed to be completely dead in the most basal region (0-L/3) which corresponds to high frequencies over $6 \mathrm{kHz}$. This assumption is in line with the experimental observations which suggest that the OHCs located in most basal regions of the mammalian cochlea are significantly more vulnerable to acoustic overstimulation than the hair cells in apical areas (Fu-Guan et al., 2012; Lim et al., 2008; Pyykkö et al., 2003). Moreover, half of the OHCs located in the middle one third of the cochlear length are assumed dead. These dead cells are assumed to be uniformly mixed with the functional cells in the sense that the cochlea, on average, maintains $50 \%$ of activity in the region. This region is tuned to middle high-frequencies between 2 and $6 \mathrm{kHz}$. It has been reported that a majority of destructive noises such as those in building construction environments and those produced by farming equipment lie in this frequency range (Pyykkö 
et al., 2003). Finally, the OHCs which are located in the most apical regions are assumed to be intact and fully active (100\% integrity) in consistence with the experimental observations (Fu-Guan et al., 2012; Lim et al., 2008; Pyykkö et al., 2003).

The results are illustrated in Fig. 7(b) of paper IV. It demonstrates a mild amplification loss (approximately $10 \mathrm{~dB}$ ) at low frequencies followed by a sharply sloping loss for frequencies above $1.5 \mathrm{kHz}$ which reaches a maximum of $82 \mathrm{~dB}$ at $4.1 \mathrm{kHz}$ and slightly improves thereafter. This prediction reasonably matches with the clinical 'noise-induced phenotype' (Schmiedt, 2010), shown by the error bars.

To quantitatively study how the location, severity and length of the OHC lesions affects the character of the cochlear amplification loss, a number of scenarios have been simulated [Fig. 8(a) and Fig. 9(a) in paper IV] whereby there are variations in the location, severity and length of the OHC lesions. The results are shown in Fig. 8(b) and Fig. 9(b) of paper IV. The results indicate that the form of the amplification loss remained similar for all those cases while the steepness and the depth of the corresponding notch varied significantly according to the location and depth of the damage to the OHCs.

\subsection{Model Predictions vs. the Animal Data}

Lim et al. (2008) exposed a group of BALB/c hybrid mice to white noise at $122 \mathrm{~dB}$ SPL during 3 consecutive days, 3 hours per day and observed the morphological changes in the OHCs along the cochlear length due to the noise exposure, as well as the resulting threshold elevations. Their results showed that shortly after the noise exposures there were about $90 \%$ intact $\mathrm{OHCs}$ at the distance of $10 \%$ from the apex, corresponding to the most apical region. However, the percentage of these intact cells significantly decreased toward the base of the cochlea, reaching a solely $40 \%$ survival rate at the distance of $82 \%$ from the apex (basal area). These experimental data are shown by circles in Fig. 5(a) of paper IV and are interpolated with an exponentially decaying function.

To simulate the effect of this specific configuration of the $\mathrm{OHC}$ death, for each partition, the magnitude of the somatic motor [Eq. (7) in paper III] is multiplied by the corresponding integrity rate. The result is depicted in Fig. 5(b) of paper IV where the model prediction is shown versus the experimentally measured threshold elevations of the noise-damaged mice cochleae at 4, 8, 16 and $32 \mathrm{kHz}$ (Lim et al., 2008). 



\section{CLINICAL IMPLICATIONS}

\subsection{Overview}

The purpose of this clinical study (paper V) is to understand how the predictions of the cochlear model (chapters 2, 3 and 4) can be interpreted in the 'human clinical world'. In other words, the idea is to validate the model predictions in a clinical relevant sample of subjects with normal as well as impaired hearing. It is of particular interest to study how differently the two hearing impaired groups, ARLH (presbyacusis) vs. NIHL, perform on auditory tests. Furthermore, it is of interest to investigate how the cochlear model can help interpret the clinical scores and understand what specific inner-ear pathologies they may point to.

A test battery of auditory tests, consisting of four psychoacoustic tests, two physiological tests and one cognitive test, was implemented to clinically assess the changes in the spectral and temporal features of the auditory system due to ARLH and NIHL. The tests were carried out on three groups of listeners: 1) ARLH: senior subjects with substantially age- related hearing loss (presbyacusis), 2) NIHL: subjects with a clear history of exposure to destructive noise, and 3) a group of normal-hearing adults (reference group).

\subsection{The subjects}

A group of twenty participants with normal hearing (12 males, 8 females) with a mean age of 37.1 years $(\mathrm{SD}=7.5)$ who had no more than $20 \mathrm{~dB} \mathrm{HL}$ at any of the frequencies between 0.125 and $8 \mathrm{kHz}$ participated in this study. Besides, a group of twenty older subjects (11 males, 9 females) with a mean age of 67.6 years $(\mathrm{SD}=1.26)$ were recruited. They had no history of noise exposure such as working in noisy environments or involving in activities associated with excessive noise exposure. They were chosen among those whose hearing impairment had been primarily diagnosed as 'age-related' (presbyacusis). Finally, a group of seven subjects (all male) diagnosed with NIHL with a mean age of 49.5 years (SD=6.67) were recruited. The participant's air-conduction hearing thresholds were obtained at frequencies between 0.125 and $8 \mathrm{kHz}$ and the corresponding audiograms are illustrated in Fig. 1 of paper V.

Candidates with any of the following conditions were excluded from the study: 1) severe tinnitus, 2) hyperacusis, 3) chronic cardiovascular diseases, hypertension requiring medication, diabetes requiring medicatiopn, 4) asymmetric hearing loss, 5) autoimmune diseases, 6) exposure to ototoxic drugs and 7) diagnosis of cancer. 


\subsection{The Test Battery}

As shown in Fig. 5-1 below, the test battery consists of psychoacoustic, physiological and cognitive tests. These tests were carried out on the subjects (section 5.2) in an acoustically isolated sound booth at the hearing clinics of Linköping University Hospital. The auditory experiments in this study were carried out monaurally on the best ear of the participant, or the right ear in case of totally symmetric hearing, except for the Hearing In Noise Test (section 5.3.4) which was carried out binaurally. It took approximately 3 hours per participant to perform the entire test battery.

\section{Psychoacoustic tests}

- Psychoacoustic tuning curves (PTCS)

- Forward temporal masking (FTM)

- Categorical loudness scaling (CLS)

- Hearing-in-noise (HINT)

\section{Physiological tests}

-Auditory brainstem responses (ABR) - Distortion product OtoAcoustic Emissions (DPOAEs)

Fig.5-1. The test battery.

\subsubsection{PTCs: a measure of frequency sensitivity and tuning}

Frequency selectivity (tuning) is one of the key features of the auditory system. The frequency tuning is believed to begin as early as in the cochlea due to the filtering that occurs by the organ of Corti (Moore, 2003). Sensorineural hearing impairments, often associated with inner-ear pathologies, lead to both elevated hearing thresholds and reduced frequency sensitivity (Glasberg and Moore, 1986). The frequency sensitivity is usually obtained through masking experiments; one such example is the psychophysical tuning curves (PTCs). During the PTC test a sinusoidal tone fixed in frequency and intensity is presented as the target signal. The tone is accompanied with a narrow-band noise (masker). For different masker center frequencies the level of the masker is increased/decreased in an adaptive manner and the lowest masking level required to mask the tone (target) is determined.

If the masker center frequency and its bandwidth are chosen properly, the masking levels would shape a curve known as the psychophysical tuning curve (PTCs). The curve's sharpness then is regarded as a measure of the frequency sensitivity (Moore, 2003). Assessing the PTCs clinically is a time-demanding procedure, however, Sek et al. (2005) introduced a fast method based on Bekesy's threshold estimation technique. This method was here implemented in MATLAB to assess the PTCs at three center frequencies: 0.5, 2 and 4 $\mathrm{kHz}$. 


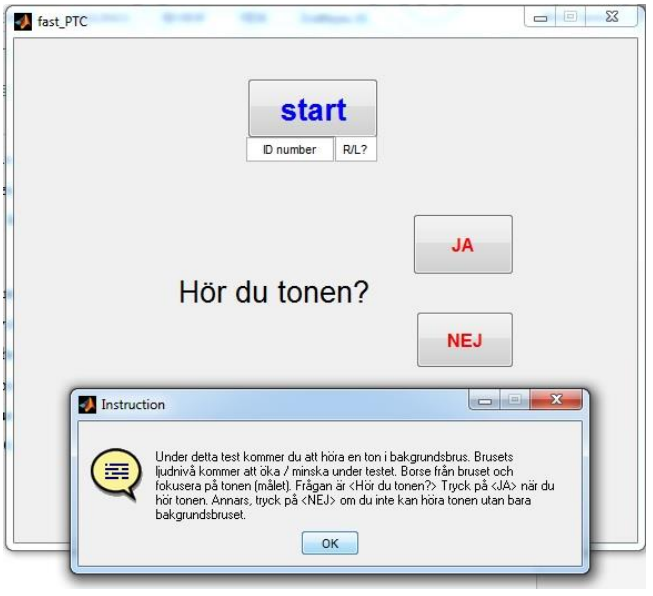

Fig. 5-2. The user-interface for the PTC test. The instruction says: 'During this test you will hear a tone in background noise. The intensity of the noise will increase/decrease. You always focus on the tone and answer to the question 'Do you hear the tone?' accordingly'.

\subsubsection{FTM: a measure of temporal resolution}

In order to perceive sounds properly in every-day circumstances, the listener must be able to resolve several simultaneous acoustic cues that vary over time both in the target signal (speech, music) and in the interfering background sounds (noise). This requires a high temporal resolution of the auditory system. To assess the temporal resolution, we use the temporal masking paradigm which classically consists of a relatively long masker (noise) followed by a silent gap and then a brief signal (target). During the test, the hearing threshold of the target is measured as a function of the gap duration (Fulton, 2010).

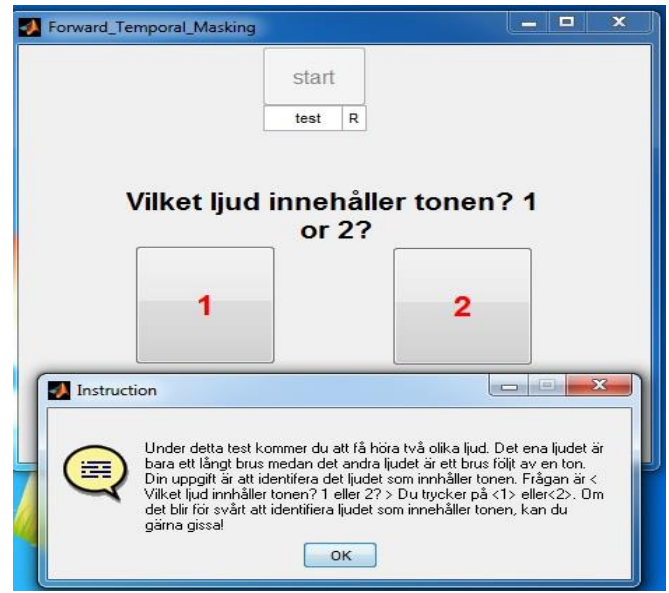

Fig. 5-3. The user-interface for the FTM test. The instruction says: 'During this test you will hear two different sounds. One of them is noise whereas the other one consists of noise followed by a tone. The question is 'which sound contains the tone?' You answer accordingly. You are welcome to guess if it becomes too hard.'

\subsubsection{CLS: a measure of loudness perception}

The human ear has a remarkable dynamic range of incoming sound intensities (Glasberg and Moore, 1986). Loudness is an attribute of the auditory sensation according to which sounds 
can be categorized on a scale from very quiet to very loud. This definition implies that loudness is a subjective quantity and, thus, can be measured only indirectly (Moore, 2003). Brand and Hohmann (2002) introduced an adaptive procedure to assess the loudness function by adjusting the presentation levels to the subject's individual auditory dynamic range. The stimuli are 2.5 second long in total and consist of a 1-second narrow band noise which is repeated twice with a 500-ms silence in between. After each stimuli, the listener is asked to rate the loudness of the stimuli by choosing from an 11-step scale (ranging from 'inaudible' to 'too loud'). The intensity of the stimuli varies according to the listener's answers in an adaptive manner (Brand and Hohmann, 2002; Stenfelt and Zeitooni, 2013) to estimate the loudness function.

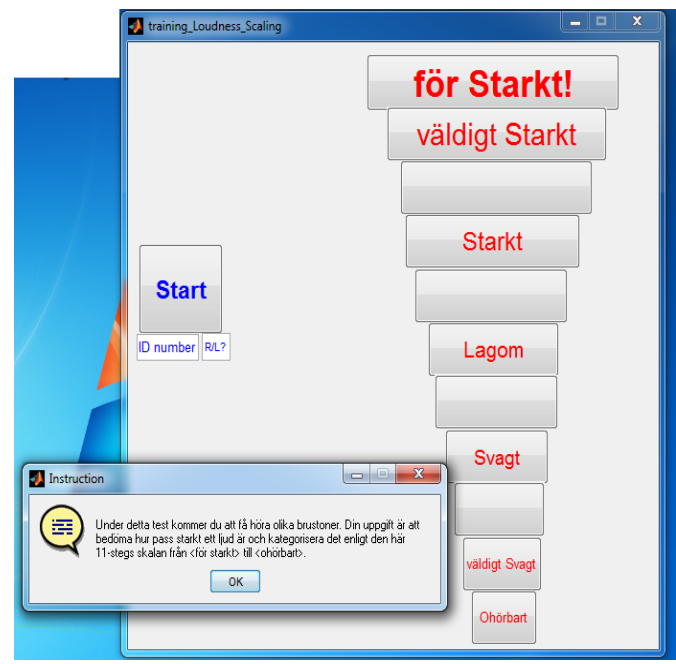

Fig. 5-4. The user-interface for the CLS test. The instruction says: 'During this test you will hear a sound at various intensities. Your task is to judge its intensity according to the 11-step scale from 'inaudible' to 'Too loud'.

\subsubsection{HINT: a measure of speech perception in noise}

Nilsson et al. (1994) developed a psychoacoustic experiment to assess the speech reception threshold in noise. Hällgren et al., (2006) introduced a Swedish version of the test comprising everyday Swedish sentences, 3 to 7 words each, with less than $\pm 2 \mathrm{~dB}$ overall fluctuation in the sound intensity. The background noise was a broad band noise with a spectrum similar to that of speech (Hällgren et al., 2006).

During the test, the sentences were played in the background noise and the participant was asked to repeat after each sentence. The initial signal to noise ratio (SNR) was set at $2 \mathrm{~dB}$ for the normal-hearing participants and at $12 \mathrm{~dB}$ for the hearing impaired subjects. The SNR was reduced by a step of $-1 \mathrm{~dB}$ each time the participant repeated the sentence correctly whereas it was increased by a $+1 \mathrm{~dB}$ step whenever the answer was incorrect. The SNR required for $50 \%$ 
correct performance (i.e., correct repetition of $50 \%$ of the sentences) was then estimated from the listener's responses.

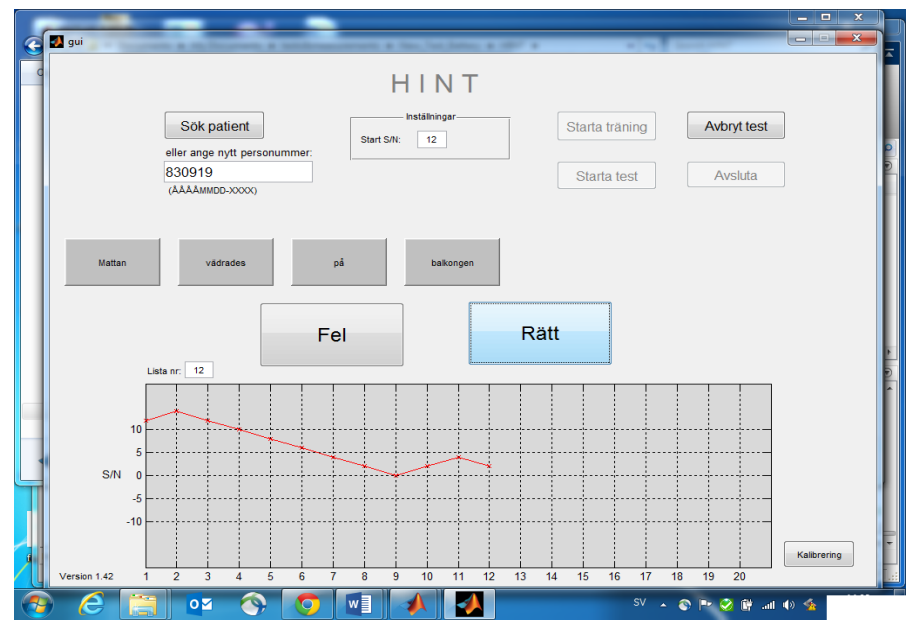

Fig. 5-5. The userinterface for the HINT test (Hällgren et al., 2006). The participant is orally instructed to repeat after each sentence. The experimenter decides if the sentence is correctly repeated or not and pushes the corresponding button. With permission from Mattias Hällgren, $\mathrm{PhD}$.

\subsubsection{DPOAE: a measure of the OHC integrity}

The OAEs are sounds which are generated by the spontaneous mechanisms in mammalian inner ears and are attributed to the active cochlear amplification (Kemp, 1978). Since the active motile forces produced by the $\mathrm{OHCs}$ (the $\mathrm{OHC}$ somatic motor) are regarded as the main source of the cochlear amplification, assessing the OAEs can provide valuable diagnostic information by giving a direct measure of the OHCs status (Stenfelt, 2008).

In the current study, the Distortion Product OAEs (DPOAEs) were measured using a pair of evoking stimuli at intensities $L_{1}$ and $L_{2}$ and at frequencies $f_{1}$ and $f_{2}$, respectively. The most prominent frequency of the recorded OAE, generated by spontaneous cochlear mechanisms, is at $2 f_{1}-f_{2} \mathrm{~Hz}$, known as the cubic distortion frequency (Neely et al., 2003) and denoted by $f_{d p}$. The DPOAEs are recorded for different $L_{2}: L_{1}$ and $f_{2}: f_{1}$ ratios including a total number of 9 measurement points as described in Eq. (5-1) below where $f_{2}$ equals the probe frequencies $0.5,2$ and $4 \mathrm{kHz}$. The $f_{2}: f_{1}$ ratio is set to be 1.22 and thus the distortion frequencies $\left(f_{d p}\right)$ are 318,1278 and $2556 \mathrm{~Hz}$ for the three cases below, respectively. Furthermore, $L_{1}$ is chosen $40,60,70 \mathrm{~dB}$ SPL and $L_{2}$ is set to be always $10 \mathrm{~dB}$ lower than the $L_{1}$ value $\left(L_{2}=L_{1}-10\right)$. 


$$
\left\{\begin{aligned}
& \text { 1) } f_{1}=409 \mathrm{~Hz}, f_{2}=500 \mathrm{~Hz}\left\{\begin{array}{l}
L 1=40 \mathrm{~dB} S P L, L_{2}=30 \mathrm{~dB} S P L \\
L 1=60 \mathrm{~dB} S P L, L_{2}=50 \mathrm{~dB} S P L \\
L 1=70 \mathrm{~dB} S P L, L_{2}=60 \mathrm{~dB} S P L
\end{array}\right\} \\
& \text { 2) } f_{1}=1639 \mathrm{~Hz}, f_{2}=2000 \mathrm{~Hz}\left\{\begin{array}{l}
L 1=40 \mathrm{dBSPL}, L_{2}=30 \mathrm{~dB} S P L \\
L 1=60 \mathrm{dBSPL}, L_{2}=50 \mathrm{~dB} S P L \\
L 1=70 \mathrm{dBSPL}, L_{2}=60 \mathrm{~dB} S P L
\end{array}\right\} \\
& \text { 3) } f_{1}=3278 \mathrm{~Hz}, f_{2}=4000 \mathrm{~Hz}\left\{\begin{array}{l}
L 1=40 \mathrm{dBSPL}, L_{2}=30 \mathrm{~dB} S P L \\
L 1=60 \mathrm{dBSPL}, L_{2}=50 \mathrm{~dB} S P L \\
L 1=70 \mathrm{dBSPL}, L_{2}=60 \mathrm{~dB} S P L
\end{array}\right\}
\end{aligned}\right\}
$$

The experiment was carried out monaurally on the participant's best ear using the Interacoustics Eclipse system (Interacoustics A/S, Assens, DK). The recordings also contain background noise; the strength of the OAE signal in comparison with the noise (DPOAE/Noise) at all of the 9 measurement points is computed as well. To assure the validity of the measurements a criterion for the DPOAE/Noise level of $4 \mathrm{~dB}$ was used. The measurements at DPOAE/Noise ratios lower than $4 \mathrm{~dB}$ are considered invalid and the OAEs are reported as 'undetectable'.

\subsubsection{ABR: a measure for status of the neural system}

The ABRs are electrical potentials recorded by electrodes placed on the scalp. These electrical potentials are elicited by acoustic stimulation and represent the ongoing electrical activity through the auditory neural pathways and in the brainstem. The result of an ABR test is a series of 5 vertex positive peaks (waves) which are approximately $1 \mathrm{~ms}$ apart from each other and typically have amplitudes of about 100-500 nanovolts (Delgado and Özdamar, 1994). Each of these five waves is generated from a specific structure in the auditory system. In the current study, wave I and V are analyzed which are generated by synchronous electrical activity of the afferent auditory nerve and the inferior colliculus, respectively (Delgado and Özdamar, 1994). The ABRs were recorded in response to a series of 2000, 150-ms long click using the Interacoustics Eclipse system. The experiment was performed monaurally on the best ear at two stimulation levels: $75 \mathrm{~dB}$ SPL and $85 \mathrm{~dB}$ SPL.

\subsubsection{Reading-span test: a measure of the working-memory capacity}

The working memory acts as an interface between the incoming sound-induced neural signal transmitted by the cochlea from one side, and the mental lexicon in the central auditory system, from the other side (Rönnberg et. al, 2013). Baddely et al., (1985) introduced a dualtask cognitive test, known as the reading span test, to measure the working memory capacity. 
Rönnberg et al., (1989) developed the Swedish version of the experiment; here, a 24 sentences version was used (each sentence consists of 3 words).

The sentences are visually presented on a computer monitor with a 3-second pause in between during which the participants are instructed to press 'YES' if the sentence is logical and press 'NO' if it is not. The test begins with two-sentence sets, followed by three-sentence sets, and so forth, up to five-sentence sets. After the set has been presented, participants are requested to recall either the first or the last words of the sentences in the correct sequential order.

\subsection{Clinical Results vs. Model Predictions}

The results of the tests are shown in Fig. 2, 3, 4, 5, 6, 7 and 8 of paper V for the three groups of the participants. These clinical tests cannot provide in-depth isolated measures of the inner ear because they may also involve more central processes. However, the 'footprints' of the model predictions can still be traced in these clinical data. Also, the results of the tests can be analysed to help validate the model predictions.

The model quantitatively predicted (paper II, III and IV) that the pathologies associated with metabolic presbyacusis and NIHL lead to reduction of the cochlear amplifications [Fig. 8 in paper III and Fig. 3(b) in paper IV] as well as flattening of the frequency response. The PTCs (as seen in Fig. 2 of paper V) clinically confirm the model prediction. Furthermore, the broadenings of the tuning curves for the hearing impaired groups are mostly manifested on the low-frequency side of the curve. This is in line with the predictions of the model which indicate that as the active processes decline (due to inner-ear pathologies) the flattening of the amplification curve is primarily observed on the low-frequency side of the curve rather than on its high-frequency side.

Paper III quantified the reduction of the firing rate of the auditory nerve due to age-related strial degenerations [Fig. 9(a) in paper III]. Various experimental studies have shown that the reduction of the firing rate is directly linked to loss of temporal resolution, impairment of phase locking and the decline of temporal coding in the mammalian cochleae (Kurt et al., 2012; Anderson et al., 2012). The results of the clinical study here (Fig. 3 in paper V) demonstrate that the presbyacusis group, unlike the other two groups, gained almost no benefit for the temporal cues provided by the gap duration in the FTM test. Moreover, according to Fig. 7(a) of paper V, the amplitude of wave V was lower while the latency was shorter in the presbyacusis group compared with the NIHL group. These results suggest that 
more of the high frequency neurons fire in the presbyacusis group (shorter latency) but they are less synchronous (lower amplitude). This is also in line with the model prediction as well as other findings indicating that phase-locking is worse in older subjects compared with younger subjects (Pichora-Fuller et al., 2006; Anderson et al., 2012).

Furthermore, the model quantitatively simulated how the changes in the biomechanics of the mechanoelectrical transduction (MET) channels due to acoustic overstimulation lead to the impairment of the loudness growth. [Paper IV, Fig. 4 (b)]. This is consistent with the clinical results (Fig. 5 in paper V) that indicate the reduction of the dynamic range in the hearingimpaired subjects.

We reasoned based on the governing equations of the model (paper III) that the DPOAEs stay relatively robust for the aging cochlea since they originate from the rest position of the MET channels which is not affected by the age-related strial degeneration. We concluded further that the DPOAE levels reflect the OHC status rather than the strial integrity. The clinical results shown in Fig. 6 of paper $\mathrm{V}$ confirm this reasoning in the sense that the DPOAEs recorded from the NIHL participants were drastically weaker than those recorded from the aged ears. This is the case even if the NIHL participants suffer from a less severe hearing loss in comparison with the aged participants, according to the audiograms shown in Fig. 1 of paper $\mathrm{V}$.

This is also in line with the outcome of the clinical study by He and Schmiedt (1996) where they compare the DPOAE levels recorded from an aged group with those recorded from a group of hearing impaired young individuals. Their results demonstrate that aged subjects can have much greater hearing losses before the decline of the otoacoustic emissions becomes notable as compared to young subjects. They hypothesize that this may be mainly because the hearing loss of the young group is likely to take root from noise exposure which acts directly on the $\mathrm{OHC}$ function, whereas the substantive cause of the hearing loss in the aged group is more likely to be of strial origin. 


\section{CONCLUSION}

\subsection{Summary}

In this thesis a physiologically-based model of mammalian cochlea was presented where the parameters of the model convey biological interpretations of the mammalian cochlear structures, in so far as known. The model was used for simulating the effects of specific inner-ear pathologies on the temporal and spectral characteristics of the cochlear responses and the auditory functions. In other words, this modeling work quantitatively related specific cellular lesions to certain changes in the auditory system, by bridging between 'biology' and 'acoustics' in an inter-disciplinary context. It was shown that the model can reasonably reproduce the experimentally measured animal data. Furthermore, the predictions of the model could also be traced and validated in human clinical data.

The model was exploited to simulate the cellular lesions associated with two very common types of sensorineural hearing impairments: metabolic presbyacusis and NIHL. The results showed that age-related degeneration of stria vascularis (metavolic presbyacusis) causes a reduction in the receptor current induced by the mechanoelectrical transduction which led to a drastic decrease in the magnitude of the active force generated by the $\mathrm{OHC}$ somatic motor (electromotility). The decline of the cochlear amplification was more pronounced at higher frequencies and the simulation results manifested a reasonable match with the high-frequency threshold elevations in aged and Furosemide-treated gerbils. Moreover, it was shown that the EP reduction interferes with the release rate of the neurotransmitter at the IHC-AN synapse which can directly contribute to the decline of temporal coding in the aging auditory system. Furthermore, the model was exploited to simulate the effects from the cellular lesions caused by acoustic overstimulation on the cochlear responses. The simulations demonstrated that as the micromechanics of the stereocillia transduction channels is altered due to the traumatic acoustical overstimulation, the compressive/nonlinear behavior of the cochlear amplifier is notably modified. This leads to an impaired loudness function reminiscent of the recruitment phenomenon. Moreover, when a severe noise-induced loss of outer hair cells is assumed at basal regions of the cochlea, the model predicts a mild loss at lower frequencies followed by a steeply sloping notch-like amplification loss of approximately $80 \mathrm{~dB}$ around $4.5 \mathrm{kHz}$. This prediction was reasonably in line with the threshold elevations observed clinically from noise-damaged human ears. 
The final part of the thesis presented a clinical study, consisting of several psychoacoustic, electrophysiological and cognitive tests, which were carried out on three groups of participants: 1) ARLH [presbyacusis], 2) NIHL and, 3) normal-hearing. The goal was to analyze how these three groups perform on the tests and how the results can be interpreted with the help of the presented model to pinpoint specific lesions inside the cochlea. Although, the ARLH and NIHL groups had comparable amount of audiometric hearing loss, their results on the tests differed.

The results of the forward temporal masking test showed that the NIHL participants benefit from the temporal cues to some extent. However, the ARLH participants gained almost no benefit from the temporal cues. This is consistent with the model prediction of the temporal deficiency due to presbyacusis which indicates that the decline of temporal coding is of agerelated nature. Besides, the DPOAEs recorded from the NIHL ears were much weaker than those from the ARHL. This is also consistent with the predictions of the model indicating that the DPOAEs are less affected by the strial degeneration (metabolic presbyacusis) than by the noise-induced $\mathrm{OHC}$ damages. Moreover, according to the brainstem data, more of the high frequency neurons fire in the presbyacusis group (shorter latency) but they are less synchronous (lower amplitude). This is in line with the model predictions as well as other findings indicating that phase-locking is worse in older subjects compared with younger subjects (Pichora-Fuller at al., 2006; Anderson et al., 2012).

\subsection{Future Works}

The present model provided a simulation tool for quantitatively studying the effect of celllevel pathologies under various scenarios on the cochlear response by defining three key parameters: 1. the location and the range of the damage along the cochlear length, 2 . the severity rate of the damage at these locations, and 3. the level of the age-related EP reduction. The arbitrary number of the partition $(\mathrm{N})$ can be set to the total number of OHCs so that the above parameters can be defined for each cell independently. This provides a resolution high enough to simulate the consequences of the damage to a single cell on the entire cochlear response. From another perspective, the model can, vice versa, relate a specific audiometric loss to the above three parameters using appropriate machine learning algorithms. In other words, it can potentially provide a diagnostic tool to quantitatively relate the observed audiometric losses with specific cellular pathologies within the inner ear.

The present thesis, including the modeling work and the clinical study, focuses on the auditory periphery as the early processor of the sound. The hearing system, however, is an 
integrated system where various acoustic, neuronal and cognitive systems interact together (Stenfelt and Rönnberg, 2009). Figure 6-1 depicts the Ease of Language Understanding (ELU) model which hypothesizes how the sound-induced language input is processed by the central auditory and the cognitive system (Rönnberg et al., 2013).

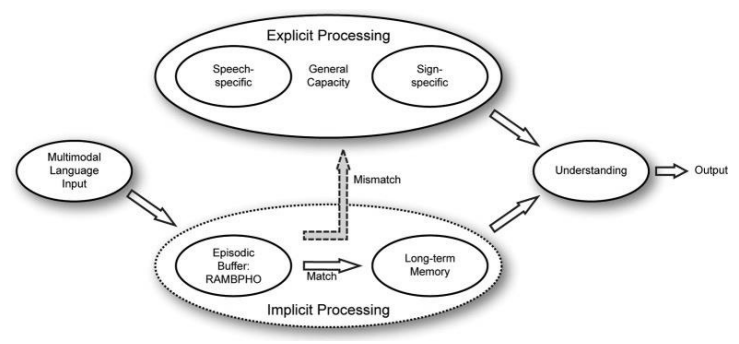

Fig. 6-1. The working memory model for Ease of Language Understanding (ELU) (Rönnberg et al., 2013). With permission from Jerker Rönnberg.

The bottom-up signal pathway, which starts from the outer ear and leads to the brain cortices, gives the classic image of the human auditory system. However, there is an increasing amount of physiological and psychoacoustic evidences for the top-down pathway whereby the brain can manipulates the auditory system and to some extent 'fine tune' the cochlea to specific acoustic cues (Katz et al., 2010; Davis and Johnsrude, 2007; Stenfelt and Rönnberg, 2009).

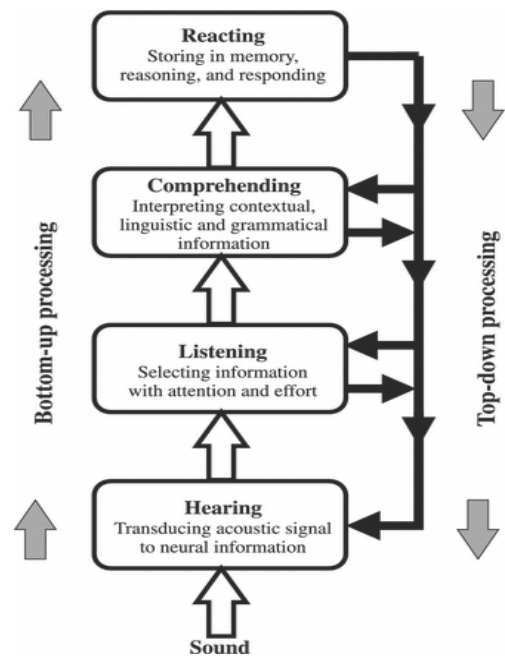

Fig. 6-2. A diagram showing bottom-up and top-down processes (Stenfelt and Rönnberg, 2009). With permission from Jerker Rönnberg.

The olivocochlear efferent network projects from the superior olivary complex at the brainstem in to the inner ear (Slepecky, 1996). It is linked to the synaptic area of the hair cells by forming a synaptic 'cistern' (Fettiplace and Nowtony, 2006). There have been various morphological investigation on the chain of actions which occur in this efferent network. This efferent network can activate nicotinic cholinergic receptors (nAChR) that change the 
membrane conductance of the outer hair cells and thereby alter the somatic motor and the active force generation in the cochlea (Katz et al., 2010).

Such top-down efferent processes are often neglected in current cochlear model. However, the presented physiologically-based model can be exploited to quantitatively study how the olivocochlear efferent network can manipulate the biomechanics of the outer hair cells and thereby modify the cochlear responses. To simulate the effect of the efferent-induced changes of the $\mathrm{OHC}$ conductance on the auditory processing, the parameter $G$ in the piezoelectric model of the OHC (Fig. 3 of paper V) has here been increased $\pm 20 \%$.

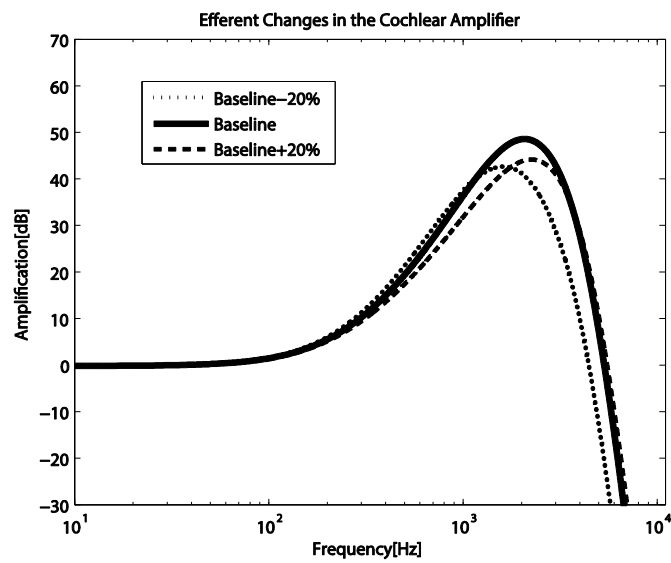

Fig. 6-3. Modification of the cochlear response due to changes in the conductance of the OHCs induced by the top-down efferent network.

Figure 6-3 illustrates the changes in the magnitude of the frequency response in the middle of the cochlear duct ( $50 \%$ of the cochlear length) due to the $\pm 20 \%$ changes in the conductance of the OHCs. As Fig. 6-3 shows, the characteristic frequency of the cochlear partition has been modified. This indicates that the position-frequency map (tuning pattern) of the cochlea has changed in the sense that the cochlear partition is now 'tuned' to another frequency. In other words, the simulation confirms that the olivocochlear efferent network can biomechanically manipulate the characteristics of the cochlear frequency responses. The biophysical model presented in this thesis provides a biomechanical foundation for simulating the efferent influence which can help better understand the mechanisms associated with top-down processes. This opens new horizons toward studying the mechanism(s) by which the brain manipulates and 'fine tunes' the auditory periphery. Moreover, physiologically-based models of the auditory nerve can be adopted and incorporated in this model in order to simulate the effects of specific neural abnormalities on the neural transmission (both afferent and efferent) of the auditory signals. 
The parameters of the model can also be updated as newer measurements are reported from inside the mammalian inner ear. Future measurements can offer more insight into the biophysics of the cochlear structures and mechanisms. These findings can be extrapolated to provide more realistic and up-to-date values for the parameters of the model. Furthermore, the clinical study can be expanded by increasing the sample size (number of participants). This is particularly vital for the NIHL group which currently consists of only 7 participants (all male) due to practical limitations and low number of NIHL candidates in the region. Moreover, other subject groups can be added to the study as it was hypothesized in section (3.3.2) that metabolic disorders, such as diabetes, can lead to premature strial degeneration reminiscent of metabolic presbyacusis. It will be of interest to explore such underlying similarities in a clinical context and collate the results with the model predictions to better understand the sources and consequences of specific inner-ear pathologies. 



\section{ACKNOWLEDGEMENT}

One day in 2009 I saw that someone at Linköping University was looking for a PhD student with technical background to create a model of the auditory periphery. Being an electrical engineer it was a remarkable change of direction. However, when I look back, despite all the difficulties, I feel that I made the right decision to involve myself in this doctoral program. The multidisciplinary nature of the hearing science gave me the chance to learn about biology, medicine, audiology and even cognitive psychology. The first person to thank is Professor Stefan Stenfelt since this project was initially his idea. I appreciate his support, trust, knowledge and, of course, his eccentric sense of humor.

This doctoral journey, which took 4 years and 5 months, gave me the chance to meet many interesting people including fellow $\mathrm{PhD}$ students at HEAD, who I do not name here, but their memories will last forever. I was lucky to have great teachers such as Professor Kathy Pichora-Fuller who encouraged me to walk in the darkness. She also connected me to the most appropriate people worldwide who could help me grow my understanding of the hearing system. I would like to use this opportunity to thank Professor Johan Carlson, who taught me signal processing, and Professor Torbjörn Löfkvist, who gave me my first research job in Sweden, at Luleå Technical University as well as Professor Morteza Nourian at K.N.Toosi University of technology, who taught me basics of engineering.

The last part of this project, which involved clinical data collection, was not possible without the valuable guidance of my co-supervisor Dr. Elina Mäki-Torkko as well as two great audiologists at the hearing clinic, Helena Torlofson and Tomas Bjuvmar. I would like to thank the anonymous test subjects who attended my clinical study, for their cooperation and patience. If they happen to read this, I want them to know that it was a pleasure for me to meet every single one of them.

The cover image of this thesis depicts an x-ray image of a cochlea inside the cadaveric temporal bone of a human. This has been done using CT-scan technique and MevisLab software. I appreciate Olivier Cros (PhD student at IMT, Linköping University) for providing me with this outstanding image of the human cochlea. This imaging project is run by Oliver Cros, Professor Hans Knutsson and Dr. Mats Andersson. I would also like to thank Mehrnaz Zeitooni, fellow PhD candidate at division of technical audiology, for her friendly help in preparing this dissertation. 
I would also like to use this opportunity to thank my lovely parents for all their endeavors, motivations and sacrifices for me to continue my education. Last but not least, I would like to thank Ghazal for her kindness and empathy. She came to my life in the last year of my doctoral program with all the hard work, stress and long days associated with it. However, she made life so easy and beautiful for me that I would have never imagined it before. ${ }^{i}$

' I acknowledge IHV (Swedish institute for disability research) for funding this doctoral project through HEAD (HEaring And Deafness) graduate school. I also acknowledge Hörselskadades Riksförbunds Hörselforkningsfonden for their financial support during the last three months. 


\section{REFERENCES}

Allen, J. B., Hall, J. L., Jeng, P. S. (1990). "Loudness growth in 1/2- octave bands- A procedure for the assessment of the loudness," J. Acoust. Soc. Am. 88, 745-753.

Anderson, S., Parbery-clark, A., White-schwach, T., Kraus, N. (2012). "Aging Affects Neural Precision of Speech Encoding," J. Neurosc. 32(41): 14156-14164.

Bekesy, G. V. (1928). "Zur Theorie des Hörens in die Schwingungsform der Basilarmembran". Phys Zeits. 29, 793-810.

Bekesy, G. V. (1960). "Part 4: Cochlear Mechanics" in Experiments in the Hearing (McGraw-Hill, New York, USA), pp 403-703.

Barkeshli, M., (1975). ,"the music of Farabi", (Iranian suprem council of culture and art, Tehran, Iran), pp 1-110.

Bohne, B.A., Harding, G.W., \& Lee, S.C. (2007). "Death pathways in noise-damaged outer hair cells, " Hearing Res. 223, 61-70.

Brand, T. and Hohmann, V. (2002). "An adaptive procedure for categorical loudness scaling," J Acoust Soc Am. 112(4), 1597-1604.

Caloz, C., Itoh, T. (2005). "Electromagnetic Metamaterials: Transmission Line Theory and Microwave Applications, " Willey-IEEE press, UK., pp 1-376.

Chen, F., Zha, D., Fridberger, A., Zheng, J., Choudhury, N., Jacques, S. L., Wang, R. K., Shi, X., and Nuttall, A. L. (2011). "A differentially amplified motion in the ear for nearthreshold sound detection," Nature neuroscience 14, 770-774.

Classon, E., Rudner, M. \& Rönnberg, J. (2013). "Working memory compensates for hearing related phonological processing deficit, " Journal of Communication Disorders, 46, 17-29. doi:10.1016/j.jcomdis.2012.10.001

Clavelin, M. (1974). "The Natural Philosophy of Galileo, " MIT Press, USA. pp. 1-148.

Cooper, N. P. (1998). "Harmonic distortion on the basilar membrane in the basal turn of the guinea-pig cochlea," J. Physiology. 509 ( Pt 1), 277-288.

Davis, A. C., (1989). "The prevalence of hearing impairment and reported hearing disability among adults in Great Britain, " Int J Epidemiol. 18(4), 911-917. 
Davis, A., Moorjani, P., (2003) "The epidemiology of hearing and balance disorders" in the book "Textbook of Audiological Medicine: Clinical Aspects of Hearing and Balance," MD group, UK. pp 89-100.

Davis, M. H. and Johnsrude, I. S. (2007). "Hearing speech sounds: top-down influences on the interface between audition and speech perception, " Hear Res. 229(1):132-47.

De Boer, E., and Nuttall, A. L. (2000). "The mechanical waveform of the basilar membrane. III. Intensity effects," J. Acous. Soc. Am. 107, 1497-1507.

Delgado, R. E., Özdamarn, Ö. (1994). "Automated Auditory Brainstem Response Interpretation, " IEEE 110, 227-237.

Ding-Pfennigdorff, D., Smolders, J., W., Muller, M., Rainer, K. (1998). "Hair cell loss and regeneration after severe acoustic overstimulation in the adult pigeon," Hearing Res. 120:109-120.

Dubno, J. R., Horwitz, A. R., \& Ahlstrom, J. B. (2003). "Recovery from prior stimulation: Masking of speech by interrupted noise for younger and older adults with normal hearing, " J Acoust Soc Am. 113(4), 2084-2094.

Fettiplace, R., Crawford, A. C., and Kennedy, H. J. (2005). "Signal transformation by mechanotransducer channels of mammalian outer hair cells.," Auditory Mechanisms: Proceedings of the 9th International Symposium, Portland USA. 1, 245-252.

Fettiplace, R., and Hackney, C. M. (2006). "The sensory and motor roles of auditory hair cells," Nature reviews. Neuroscience 7, 19-29.

Fukushima, H., Cureoglu, S., Schachern, P. A., Paparella, M. M., Harada, T., and Oktay, M. F. (2006). "Effects of type 2 diabetes mellitus on cochlear structure in humans," JAMA Otolaryngol Head Neck Surg. 132, 934-938.

Fulton, Susan E. (2010). "The effects of aging on temporal masking," Graduate School Theses and Dissertations: http://scholarcommons.usf.edu/etd/1636, last viewed: 30 November 2013.

Ghaffari, R., Aranyosi, A. J., and Freeman, D. M. (2007). "Longitudinally propagating traveling waves of the mammalian tectorial membrane," PNAS 104, 16510-16515.

Glasberg, B.R. \& Moore, B.C.J. (1986). "Auditory filter shapes in subjects with unilateral and bilateral cochlear impairments," J Acoust Soc Am. 79, 1020-1033. 
Gordon-Salant S., Frisina, R. D. (2010). "Introduction and overview," in The Aging Auditory system, edited by Gordon-Salant S. F., Fristina, R. D., Popper, A. N., Fay, R, R. (Springer Science+Business Media, USA ), pp. 1-8.

Greenwood, D. D. (1990). "A cochlear frequency-position function for several species - 29 Years Later," J. Acous. Soc. Am. 87, 2592-2605.

Gummar, A.W., Hemmert, W., Zenner, H. (1996) "Resonant tectorial membrane motion in the inner ear: Its crucial role in frequency tuning" Proc. Natl. Acad. Sci. USA. 93, 87278732.

Gundersen, T., Skarstein Ø., and Sikkeland T. (1978) "A Study of the Vibration of the Basilar Membrane in Human Temporal Bone Preparations by the Use of the Mössbauer Effect." Acta Otolaryngology $86,225-32$.

Guthrie, W. K. C. (1978), "A history of Greek philosophy," Volume 1: The earlier Presocratics and the Pythagoreans, Cambridge University Press, UK. pp 1-175.

He, N. J., and Schmiedt, R. A. (1996). "Effects of aging on the fine structure of the 2f1-f2 acoustic distortion product," J. Acous. Soc. Am. 99, 1002-1015.

Holt, J. R., Corey, D. P., and Eatock, R. A. (1997). "Mechanoelectrical transduction and adaptation in hair cells of the mouse utricle, a low-frequency vestibular organ," The Journal of neuroscience : J. Neurosci. 17, 8739-8748.

Hällgren, M., Larsby, B., Arlinger, S. (2006). "A Swedish version of the Hearing In Noise Test (HINT) for measurement of speech recognition," Int J Audiol. 45, 227-237.

Irino, T., and Patterson, R. D. (2001). "A compressive gammachirp auditory filter for both physiological and psychophysical data," J. Acous. Soc. Am. 109, 2008-2022.

Jia, S., Dallos, P., and He, D. Z. (2007). "Mechanoelectric transduction of adult inner hair cells," J. Neurosci. 27, 1006-1014.

Katz, E., Elgoyhen, A. B., Fuchs, P. A. (2010). "Cholinergic inhibition of hair cells," in Auditory and Vestibular Efferents, edited by Ryugo, D. K., Popper, A. N., Fay, R., R. (Springer Handbook of Auditory Research, USA ), pp. 103-133.

Kemp, D. T. (1978). "Stimulated acoustic emissions from within the human auditory system". J Acoust Soc Am. 64 (5): 1386-1391.

Kluk, K., Moore, B.C.J. (2004). "Factors affecting psychophysical tuning curves for normally hearing subjects," Hear Res. 194, 118-134. 
Kochkin, S. (2005). "Hearing loss population tops 31 million people". Hear Rev, 12(7), 1629.

Kros, C. J. (1996). "Hair cell physiology" in The Cochlea, edited by edited by Dallos, P., Popper, A., N., Fay, R., R. (Springer-Verlag, New York, USA), pp. 318-385.

Kujawa, S. G., Liberman, C. (2009). "Adding Insult to Injury: Cochlear Nerve Degeneration after Temporary Noise-Induced Hearing Loss," J NEUROSCI. 29(45), 14077-14085.

Kurt, S., Sausbier, M., Ruttiger, L., Brandt, N., Moeller, C. K., Kindler, J., Sausbier, U., Zimmermann, U., van Straaten, H., Neuhuber, W., Engel, J., Knipper, M., Ruth, P., and Schulze, H. (2012). "Critical role for cochlear hair cell BK channels for coding the temporal structure and dynamic range of auditory information for central auditory processing," FASEB J. 26, 3834-3843.

Lang, H., Jyothi, V., Smythe, N. M., Dubno, J. R., Schulte, B. A., and Schmiedt, R. A. (2010). "Chronic reduction of endocochlear potential reduces auditory nerve activity: further confirmation of an animal model of metabolic presbyacusis," J. Assoc. Res. Otolaryngol. 11, 419-434.

Li, Y., Mead, J., Grosh, K., (2011). "coupling the subtectorial fluid with the tectorial membrane and hair bundles of the cochlea," AIP: What Fire is in Mine Ears: Proceedings of the 11th International Mechanics of Hearing Workshop 1403, 104109.

Lim, H. W., Choi, S. H., Kang, H. H., Ahn, J. H., Chung, J. W. (2008). "Apoptotic Pattern of Cochlear Outer Hair Cells and Frequency-specific Hearing Threshold Shift in Noiseexposed BALB/c Mice, " CLIN. EXP. Otolaryngology, 1(2), 80-85.

Liu, Y. W., and Neely, S. T. (2009). "Outer hair cell electromechanical properties in a nonlinear piezoelectric model," J. Acous. Soc. Am.126, 751-761.

Liu, Y. W., and Neely, S. T. (2010). "Distortion product emissions from a cochlear model with nonlinear mechanoelectrical transduction in outer hair cells," J. Acous. Soc. Am. 127, 2420-2432.

Lopez-Poveda, E. A., and Barrios, P. (2013). "Perception of stochastically undersampled sound waveforms: a model of auditory deafferentation," Front. Neurosci. 7:124.

Lopez-Poveda, E. A., Barrios, L. F., Alves-Pinto, A. (2007). "Psychophysical estimates of level-dependent best-frequency shifts in the apical region of the human basilar membrane," J. Acoust. Soc. Am. 121(6), 3646-3654. 
Lopez-Poveda, E. A., and Eustaquio-Martin, A. (2006). "A biophysical model of the inner hair cell: the contribution of potassium currents to peripheral auditory compression," JARO 7, 218-235.

Lu, s. (2009). "A physiologically based nonlinear multicompartment cochlear model with a piezoelectric OHC feedback system. " in Dissertation: a nonlinear multicompartmental cochlear model, (Boston University, College of Engineering, USA), pp 45-73.

Lu, S., Mountain, D., and Hubbard, A. (2009). "Is stereocilia velocity or displacement feedback used in the cochlear amplifier?," Concepts and Challenges in the Biophysics of Hearing: Proceedings of the $10^{\text {th }}$ Internaional Workshop on Mechanics of Hearing, 297-302.

Mammano, F., Nobili, R. (2014). Alfonso Corti.Cochlea. Retrieved March 10, 2014, from http://147.162.36.50/cochlea/cochleapages/overview/corti/corti.htm

Makary CA, Shin J, Kujawa SG, Liberman MC, Merchant SN. (2011). "Age-related primary cochlear neuronal degeneration in human temporal bones, " J Assoc Res Otolaryngol. 12(6):711-717.

Marozeau, J. and Florentine, M. (2007). "Loudness growth in individual listeners with hearing losses: A review, " J. Acous. Soc. Am. 122(3), 81-83.

McFadden, S. L., Ding, D., Reaume, A. G., Flood, D. G., Salvi, R. J.(1999). ” Age-related cochlear hair cell loss is enhanced in mice lacking copper/zinc superoxide dismutase, " Neurobiol Aging. 20(1):1-8.

Meaud, J., and Grosh, K. (2010). "The effect of tectorial membrane and basilar membrane longitudinal coupling in cochlear mechanics," J. Acous. Soc. Am. 127, 1411-1421.

Meddis, R. (2006). "Auditory-nerve first-spike latency and auditory absolute threshold: A computer model, " J. Acous. Soc. Am. 119 , 406-4017.

Meddis, R., Lopez-Poveda EA. (2010). "Peripheral auditory system: from pinna to auditory nerve," in: Meddis, Lopez-Poveda, Popper, Fay (eds.) Computer Models of the Auditory System. Springer Handbook of Auditory Research, vol. 35, Springer, New York, pp 7-38.

Meddis, R., Lopez-Poveda, E., Fay, R.R., Popper, A. (2010). "Computational models of the auditory system, " Springer Handbook of Auditory Research, vol. 35, Springer, New York, pp 1-350.

Mills, J. H., Schmiedt, R. A., and Dubno, J. R. (2006). "Age-related hearing loss: a loss of voltage, not hair cells," Semin Hear. 27, 228-236. 
Moore, B. C. J. (2003). "Coding of sounds in the auditory system and its relevance to signal processing and coding in cochlear implants," Otology \& Neurotology 24, 243-254.

Moore, B. C. J. (2003). " An introduction to the psychology of the hearing, " $5^{\text {th }}$ Edition, Acadamic Press, London, UK, pp. 127-162.

Naidu, R. C., and Mountain, D. C. (2001). "Longitudinal coupling in the basilar membrane," J. Assoc. Res. Otolaryngol. 2, 257-267.

Nam, J. H., and Fettiplace, R. (2010). "Force Transmission in the Organ of Corti Micromachine," Biophys J 98, 2813-2821.

Nam, J. H., and Fettiplace., R. (2011). "A cochlear partition model incorporating realistic electrical and mechanical parameters for outer hair cells," AIP: What Fire is in Mine Ears: Proceedings of the 11th International Mechanics of Hearing Workshop 1403, 170-175.

Neely, S. T., Gorga, M. P., Dorn, P. A. (2003) "Cochlear compression estimates from measurements of distortion-product otoacoustic emissions," J. Acous. Soc. Am. 114(3), 1499-1508.

Nilsson, M., Soli, S. D., Sullivan, J. A. (1994). "Development of the Hearing In Noise Test (HINT) for the measurement of speech reception thresholds in quiet and in noise," J Acoust Soc Am. 95, 338-352.

Niskar, A. S., Kieszak, S. M., Holmes, A. E., Esteban, E., Rubin, C., Brody, D. J. (2001) "Estimated prevalence of noise induced hearing threshold shifts among children 6 to 19 years of age: The third national health and nutritional examination survey 1988-1994, United States., " Pediatrics 108, 40-43.

Nowotny, M., and Gummer, A. W. (2005). "What do the OHCs move with their electromotility? " Auditory Mechanisms: Proceedings of the 9th International Symposium, Portland USA., 101-102.

Oxenham, A. J. (2001). "Forward masking: Adaptation or integration?," J Acoust Soc Am. 109(2), 732-741.

Pattuzi, R. (1996). "Cochlear micromechanics and macromechanics," in The Cochlea, edited by Dallos, P., Popper, A., N., Fay, R., R. (Springer-Verlag, USA), pp. 186-257.

Patuzzi, R., and Moleirinho, A. (1998). "Automatic monitoring of mechano-electrical transduction in the guinea pig cochlea," Hear. Res. 125, 1-16. 
Pichora-Fuller, K. M., Benson, N. J., Hamstra, S. J., Storzer, E. (2006). "Effect of age on detection of gaps in speech and nonspeech markers varying in duration and spectral symmetry, " J. Acous. Soc. Am. 119(2):1143-55.

Proskuryakov, S. Y., Konoplyannikov, A. G., Gabai, V. L. (2003) "Necrosis: a specific form of programmed cell death? " Experimental Cell Research 283, 1-16.

Pyykkö, I., Strack, J., Toppila, E., Ulfendahl, M. (2003). "Noise-induced hearing loss" in

Textbook of audiological medicine: clinical aspects of hearing and balance, edited by

Luxon, L. (Taylor and Francis group, United kingdom), pp. 477-494.

Ramamoorthy, S., Deo, N. V., and Grosh, K. (2007). "A mechano-electro-acoustical model for the cochlea: Response to acoustic stimuli," J. Acous. Soc. Am. 121, 2758-2773.

Riquelme, R., Cediel, R., Contreras, J., la Rosa Lourdes, R. D., Murillo-Cuesta, S., Hernandez-Sanchez, C., Zubeldia, J. M., Cerdan, S., and Varela-Nieto, I. (2010). "A comparative study of age-related hearing loss in wild type and insulin-like growth factor I deficient mice," Front Neuroanat. 4, 27.

Robertson, C. M., Tyebkhan, J. M., Peliowski A., Etches, P. C., Cheung, P. Y. (2006). " Ototoxic drugs and sensorineural hearing loss following severe neonatal respiratory failure, " Acta Paediatr. 95(2): 214-23.

Robles, L., and Ruggero, M. A. (2001). "Mechanics of the mammalian cochlea," Physiological reviews 81, 1305-1352.

Rönnberg, J., Lunner, T., Zekveld, A., Sörqvist, P., Danielsson, H., Lyxell, B., Dahlström, Ö., Signoret, C., Stenfelt, S., Pichora-Fuller, M. K., Rudner, M. (2013). "The Ease of Language Understanding (ELU) model: Theoretical, empirical, and clinical advances, " Frontiers in System Neurosc.7 (00031). DOI=10.3389/fnsys.2013.00031.

Santos-Sacchi, J. (1991). "Isolated supporting cells from the organ of Corti: some whole cell electrical characteristics and estimates of gap junctional conductance," Hear. Res. 52, 89-98.

Saremi, A., and Stenfelt, S. (2011). "A physiological signal transmission model to be used for specific diagnosis of cochlear impairments," AIP: What Fire is in Mine Ears: Proceedings of the 11th International Mechanics of Hearing Workshop 1403, pp. 369373.

Saremi, A., and Stenfelt, S. (2013). "Effect of metabolic presbyacusis on cochlear responses: A simulation approach using a physiologically-based model, " J. Acous. Soc. Am. 134 (4), 2833-2852. 
Saremi, A., and Stenfelt, S. (2014). "Effects of Acoustic Overstimulation and the Associated Cellular Lesions on the Cochlear Amplifier: Simulation Results, "J. Acous. Soc. Am. Submitted.

Saunders, J. C., Canlon, B., and Flock, A. (1986). "Changes in stereocilia micromechanics following overstimulation in metabolically blocked hair cells," Hearing Res. 24, 217-225. Schmiedt, R. A. (2010). "physiology of cochlear presbyacusis," in The Aging Auditory system, edited by Gordon-Salant S. F., Fristina, R. D., Popper, A. N., Fay, R, R. (Springer Science+Business Media, USA ), pp. 9-38.

Schmiedt, R. A., Lang, H., Okamura, H. O., and Schulte, B. A. (2002). "Effects of furosemide applied chronically to the round window: a model of metabolic presbyacusis," J. Neurosci. 22, 9643-9650.

Schuknecht, H., F. (1971), "Presbyacusis”, In: Pathology of the Ear. Cambridge, Harvard university press, MA, USA. pp 1-178.

Sek, A., Alcantara, J., Moore, C. J., Kluk, K., Wicher, A. (2005) "Development of a fast method for determining psychophysical tuning curves," Int J Audiol. 44, 408-420.

Slepecky, N. B. (1996). "Structure of the mamalian cochlea," in The Cochlea, edited by edited by Dallos, P., Popper, A., N., Fay, R., R. (Springer-Verlag, USA), pp. 44-129.

Smith, R. J., Shearer, A. E., Hildebrand, M. S., Camp, J. V., (2013). "Deafness and Hereditary Hearing Loss Overview," GeneReviews. [internet].

Stenfelt, S. (2008). "Towards Understanding the Specifics of Cochlear Hearing Loss: A Modelling Approach." Int J Audiol. 47(2), 5-10.

Stenfelt, S., and Ronnberg, J. (2009). "The Signal-Cognition interface: Interactions between degraded auditory signals and cognitive processes," Scand J Psychol. 50, 385-393.

Stenfelt, S., Puria, S., Hato, N., and Goode, R L. (2003) "Basilar Membrane and Osseous Spiral Lamina Motion in Human Cadavers with Air and Bone Conduction Stimuli," Hear Res. 181: 131-43.

Stenfelt, S., and Zeitooni, M. (2013). "Loudness functions with air and bone conduction stimulation in normal-hearing subjects using a categorical loudness scaling procedure," Hearing Res. 301, 85-92.

Stevens, S. S. (1955). “The measurement of loudness,” J. Acoust. Soc. Am. 25, 815-829. 
Stone, J. S., and Cotanche, D. A. (2007). "Hair cell regeneration in the avian auditory epithelium," Int. J. Dev. Biol. 51, 633-647.

Stuart-Hamilton, Ian (2006). "The Psychology of Ageing: An Introduction, " London: Jessica Kingsley Publishers, UK. pp 1-201.

Sumner, C. J., Lopez-Poveda, E. A., O'Mard, L. P., and Meddis, R. (2002). "A revised model of the inner-hair cell and auditory-nerve complex," J. Acous. Soc. Am. 111, 21782188.

Sulkowski, W. J., Szymczak. W., Kowalska, S., Sward-Matyja, M. (2004). "Epidemiology of occupational noise-induced hearing loss (ONIHL) in Poland," Otolaryngol Pol. 58(1):233236.

Trowe, M. O., Maier, H., Petry, M., Schweizer, M., Schuster-Gossler, K., and Kispert, A. (2011). "Impaired stria vascularis integrity upon loss of E-cadherin in basal cells," Dev Biol 359, 95-107.

Winter, I. M., Robertson, D., and Yates, G. K. (1990). "Diversity of characteristic frequency rate-intensity functions in guinea pig auditory nerve fibres," Hear. Res. 45, 191-202. 



\section{Papers}

The articles associated with this thesis have been removed for copyright reasons. For more details about these see:

http://urn.kb.se/resolve?urn=urn:nbn:se:liu:diva-105810 


\section{Studies from the Swedish Institute for Disability Research}

1. Varieties of reading disability

Stefan Gustafson

ISBN 91-7219-867-2, 2000

2. Cognitive functions in drivers with brain injury - anticipation and adaptation Anna Lundqvist

ISBN 91-7219-967-9, 2001

3. Cognitive deafness

Ulf Andersson

ISBN 91-7373-029-7, 2001

4. Att lära sig leva med förvärvad hörselnedsättning sett ur par-perspektiv

Carin Fredriksson

ISBN 91-7373-105-6, 2001

5. Signs, Symptoms, and Disability Related to the Musculo-Skeletal System Gunnar Lundberg

ISBN 91-7373-160-9, 2002

6. Participation - Ideology and Everyday Life

Anette Kjellberg

ISBN 91-7373-371-7, 2002

7. Föräldrar med funktionshinder - om barn, föräldraskap och familjeliv

Marie Gustavsson Holmström

ISBN 91-7203-500-5, 2002

8. Active wheelchair use in daily life

Kersti Samuelsson

ISBN 91-7373-196-X, 2002

9. Två kön eller inget alls. Politiska intentioner och vardagslivets realiteter i den arbetslivsinriktade rehabiliteringen

Marie Jansson

ISBN 91-7373-568-X, 2003 
10. Audiological and cognitive long-term sequelae from closed head injury Per-Olof Bergemalm

ISBN 91-7668-384-2, 2004

11. Att vara i särklass - om delaktighet och utanförskap i gymnasiesärskolan Martin Molin

ISBN 91-85295-46-9, 2004

12. Rättvis idrottsundervisning för elever med rörelsehinder - dilemma kring omfördelning och erkännande

Kajsa Jerlinder

Licentiate Degree, 2005

13. Hearing impairment and deafness. Genetic and environmental factors interactions - consequences. A clinical audiological approach

Per-Inge Carlsson

ISBN 91-7668-426-1, 2005

14. Hearing and cognition in speech comprehension. Methods and applications Mathias Hällgren

ISBN 91-85297-93-3, 2005

15. Living with deteriorating and hereditary disease: experiences over ten years of persons with muscular dystrophy and their next of kin

Katrin Boström

ISBN 91-7668-427-x, 2005

16. Disease and disability in early rheumatoid arthritis

Ingrid Thyberg

ISBN 91-85299-16-2, 2005

17. "Varför får jag icke följa med dit fram?" Medborgarskapet och den offentliga debatten om dövstumma och blinda 1860-1914

Staffan Bengtsson

ISBN 91-85457-06-X, 2005

18. Modalities of Mind. Modality-specific and nonmodality-specific aspects of working memory for sign and speech

Mary Rudner

ISBN 91-85457-10-8, 2005 
19. Facing the Illusion Piece by Piece. Face recognition for persons with learning disability

Henrik Danielsson

ISBN 91-85497-09-6, 2006

20. Vuxna med förvärvad traumatisk hjärnskada - omställningsprocesser och konsekvenser i vardagslivet. En studie av femton personers upplevelser och erfarenheter av att leva med förvärvad traumatisk hjärnskada

Thomas Strandberg

ISBN 91-7668-498-9, 2006

21. Nycklar till kommunikation. Kommunikation mellan vuxna personer med grav förvärvad hjärnskada och personernas närstående, anhöriga och personal

Pia Käcker

ISBN 978-91-85715-88-6, 2007

22. "Aspergern, det är jag”. En intervjustudie om att leva med Asperger syndrom

Gunvor Larsson Abbad

ISBN 978-91-85831-43-2, 2007

23. Sounds of silence - Phonological awareness and written language in children with and without speech

Janna Ferreira

ISBN 978-91-85895-74-8, 2007

24. Postponed Plans: Prospective Memory and Intellectual Disability

Anna Levén

ISBN 978-91-85895-57-1, 2007

25. Consequences of brain tumours from the perspective of the patients and of their next of kin

Tanja Edvardsson

ISBN 978-91-7668-572-3, 2008

26. Impact on participation and service for persons with deafblindness

Kerstin Möller

ISBN 978-91-7668-595-2, 2008

27. Approaches to Audiological Rehabilitation with Hearing Aids: studies on prefitting strategies and assessment of outcomes

Marie Öberg

ISBN 978-91-7393-828-0, 2008 
28. Social Interaction and Participation in Activities of Everyday Life Among Persons with Schizophrenia

Maria Yilmaz

Licentiate Degree, 2009

29. Focus on Chronic Disease through Different Lenses of Expertise

Towards Implementation of Patient-Focused

Decision Support Preventing Disability:

The example of Early Rheumatoid Arthritis

Örjan Dahlström

ISBN 978-91-7393-613-2, 2009

30. Children with Cochlear Implants: Cognition and Reading Ability

Malin Wass

ISBN: 978-91-7393-487-9, 2009

31. Restricted participation:

Unaccompanied children in interpreter-mediated asylum hearings in Sweden

Olga Keselman

ISBN: 978-91-7393-499-2, 2009

32. Deaf people and labour market in Sweden.

Education - Employment - Economy.

Emelie Rydberg

ISBN: 978-91-7668-725-3, 2010

33. Social rättvisa i inkluderande idrottsundervisning

för elever med rörelsehinder - en utopi?

Kajsa Jerlinder

ISBN: 978-91-7668-726-0, 2010

34. Erfarenheter av rehabiliteringsprocessen mot ett arbetsliv

- brukarens och de professionellas perspektiv

Helene Hillborg

ISBN: 978-91-7668-741-3, 2010

35. Knowing me, knowing you - Mentalization abilities of children who use augmentative and alternative communication

Annette Sundqvist

ISBN: 978-91-7393-316-2, 2010 
36. Lärare, socialsekreterare och barn som far illa - om sociala representationer och interprofessionell samverkan.

Per Germundsson

ISBN: 978-91-7668-787-1, 2011

37. Fats in Mind

Effects of Omega-3 Fatty Acids on Cognition and Behaviour in Childhood

Ulrika Birberg Thornberg

ISBN: 978-91-7393-164-9, 2011

38. "Jobbet är kommunikation"

Om användning av arbetshjälpmedel för personer med hörselnedsättning

Sif Bjarnason

Licentiate Degree. ISBN: 978-91-7668-835-9, 2011

39. Applying the ICF-CY to identify everyday life situations of children and youth with disabilities

Margareta Adolfsson

ISBN: 978-91-628-8342-3, 2011

40. Tinnitus - an acceptance-based approach

Vendela Zetterqvist

ISBN: 978-91-7393-040-6, 2011

41. Applicability of the ICF-CY to describe functioning and environment of children with disabilities

Nina Klang

ISBN: 978-91-7668-864-9, 2012

42. Bringing more to participation

Participation in school activities of persons with Disability within the framework of the International Classification of Functioning, Disability and Health for Children and Youth (ICF-CY)

Gregor Maxwell

ISBN: 978-91-628-8484-0, 2012

43. From Eye to Us.

Prerequisites for and levels of participation in mainstream school of persons with Autism Spectrum Conditions

Marita Falkmer

ISBN: 978-91-637-2091-8, 2013 
44. Otosclerosis, clinical long-term perspectives

Ylva Dahlin-Redfors

ISBN 978-91-628-8617-2, 2013

45. Tinnitus in Context - A Contemporary Contextual Behavioral Approach Hugo Hesser

ISBN 978-91-7519-701-2, 2013

46. Hearing and middle ear status in children and young adults with cleft palate Traci Flynn

ISBN 978-91-628-8645-5, 2013

47. Utrymme för deltagande, beslutsprocesser i möten mellan patienter med ospecifika ländryggsbesvär och sjukgymnaster i primär vård

Iréne Josephson

ISBN 42-978-91-85835-41-6, 2013

48. Man vill ju klara sig själv" Studievardagen för studenter med Asperger syndrom i högre studier

Ann Simmeborn Fleischer

ISBN 978-91-628-8681-3, 2013

49. Cognitive erosion and its implications in Alzheimer's disease

Selina Mårdh

ISBN 978-91-7519-621-1, 2013

50. Hörselscreening av en population med utvecklingsstörning

Utvärdering av psykoakustisk testmetod och av OAE-registrering som komplementär metod

Eva Andersson

Licentiate Degree. ISBN 978-91-7519-616-9, 2013

51. Skolformens komplexitet - elevers erfarenheter av skolvardag och tillhörighet i gymnasiesärskolan

Therése Mineur

ISBN 978-91-7668-951-6, 2013

52. Evaluating the process of change:

Studies on patient journey, hearing disability acceptance and stages-of-change

Vinaya Kumar Channapatna Manchaiah

ISBN 978-91-7519-534-6, 2013 
53. Cognition in hearing aid users: Memory for everyday speech

Hoi Ning (Elaine) $\mathrm{Ng}$

ISBN 978-91-7519-494-3, 2013

54. Representing sounds and spellings Phonological decline and compensatory working memory in acquired hearing impairment

Elisabet Classon

ISBN 978-91-7519-500-1, 2013

55. Assessment of participation in people with a mild intellectual disability

Patrik Arvidsson

ISBN 978-91-7668-974-5, 2013

56. Barnperspektiv i barnavårdsutredningar - med barns hälsa och barns upplevelser i fokus

Elin Hultman

ISBN 978-91-7519-457-8, 2013

57. Internet Interventions for Hearing Loss

Examining rehabilitation Self-report measures and Internet use in hearing-aid users

Elisabet Sundewall Thorén

ISBN 978-91-7519-423-3, 2014

58. Exploring Cognitive Spare Capacity: Executive Processing of Degraded Speech Sushmit Mishra

ISBN 978-91-7519-386-1, 2014

59. Supported employment i en svensk kontext - förutsättningar när personer med funktionsnedsättning når, får och behåller ett arbete

Johanna Gustafsson

ISBN 978-91-7529-012-6, 2014 
